Article

\title{
Directed Evolution of an Improved Rubisco; In Vitro Analyses to Decipher Fact from Fiction
}

\author{
Yu Zhou and Spencer Whitney *D
}

Australian Research Council Center of Excellence for Translational Photosynthesis, Research School of Biology, The Australian National University, 134 Linnaeus Way, Acton, ACT 0200, Australia; Yu.Zhou@anu.edu.au

* Correspondence: spencer.whitney@anu.edu.au; Tel.: +61-2-6125-5073

Received: 30 August 2019; Accepted: 4 October 2019; Published: 10 October 2019

\begin{abstract}
Inaccuracies in biochemically characterizing the amount and $\mathrm{CO}_{2}$-fixing properties of the photosynthetic enzyme Ribulose-1,5-bisphosphate (RuBP) carboxylase/oxygenase continue to hamper an accurate evaluation of Rubisco mutants selected by directed evolution. Here, we outline an analytical pipeline for accurately quantifying Rubisco content and kinetics that averts the misinterpretation of directed evolution outcomes. Our study utilizes a new T7-promoter regulated Rubisco Dependent Escherichia coli (RDE3) screen to successfully select for the first Rhodobacter sphaeroides Rubisco (RsRubisco) mutant with improved $\mathrm{CO}_{2}$-fixing properties. The RsRubisco contains four amino acid substitutions in the large subunit $(\mathrm{RbcL})$ and an improved carboxylation rate $\left(k_{\text {cat }} \mathrm{C}\right.$, up 27\%), carboxylation efficiency $\left(k_{c a t} \mathrm{C} / K_{m}\right.$ for $\mathrm{CO}_{2}$, increased $\left.17 \%\right)$, unchanged $\mathrm{CO}_{2} / \mathrm{O}_{2}$ specificity and a $40 \%$ lower holoenzyme biogenesis capacity. Biochemical analysis of RsRubisco chimers coding one to three of the altered amino acids showed Lys-83-Gln and Arg-252-Leu substitutions (plant RbcL numbering) together, but not independently, impaired holoenzyme $\left(\mathrm{L}_{8} \mathrm{~S}_{8}\right)$ assembly. An N-terminal Val-11-Ile substitution did not affect RsRubisco catalysis or assembly, while a Tyr-345-Phe mutation alone conferred the improved kinetics without an effect on RsRubisco production. This study confirms the feasibility of improving Rubisco by directed evolution using an analytical pipeline that can identify false positives and reliably discriminate carboxylation enhancing amino acids changes from those influencing Rubisco biogenesis (solubility).
\end{abstract}

Keywords: photosynthesis; carbon fixation; synthetic biology; metabolic engineering

\section{Introduction}

Ribulose-1,5-bisphosphate carboxylase/oxygenase (Rubisco) is the initial, often rate-limiting, enzyme in the photosynthetic Calvin-Benson-Bassham (CBB) cycle that converts $\mathrm{CO}_{2}$ into the pre-cursor organic molecules that underpin life in the biosphere [1]. Rubisco constitutes $20-50 \%$ of the protein in leaves and $5-25 \%$ of the protein in algae and photosynthetic prokaryotes, making it the most abundant protein on earth [2-4]. This abundance is necessary due to the slowness of the rate at which Rubisco fixes $\mathrm{CO}_{2}$ to Ribulose-1,5-bisphosphate (RuBP) to produce duplicate 3-phosphoglycerate (3PGA) molecules-a reaction completing only 2-5 cycles per second in vascular plants. The carboxylation reaction rate is also compromised by the erroneous fixation of $\mathrm{O}_{2}$ instead of $\mathrm{CO}_{2}$, producing a 3PGA and 2-phosphoglycolate (2PG), a metabolically toxic product whose recycling back into 3PGA (from two 2PG) by photorespiration consumes energy and releases fixed $\mathrm{CO}_{2}[5,6]$. In crops such as wheat and rice, $25 \%$ or more of the $\mathrm{CO}_{2}$ assimilated by photosynthesis is lost during photorespiration. Improving the carboxylation properties of plant Rubisco has therefore long been considered a valuable approach for enhancing crop photosynthesis and growth [7]. As more efficient Rubisco isoforms of an equivalent Form I structure exist naturally in some red algae, the feasibility of improving plant Rubisco appears tenable [8]. 
Form I Rubisco comprises a structurally conserved $\sim 550 \mathrm{kD}$ complex comprising a core of eight large ( $\mathrm{RbcL}$ ) subunits (arranged as a tetrad of $\mathrm{RbcL}_{2}$ dimers) capped by two tetrads of small (RbcS) subunits [9]. The eight catalytic sites in each $\mathrm{L}_{8} \mathrm{~S}_{8}$ complex are formed by conserved amino acids in each adjoining RbcL2 pair (Figure A1). While we have a relatively detailed understanding of the conserved, complex catalytic chemistry of Rubisco $[10,11]$ the rationale design of a better Rubisco remains elusive. Compounding the challenge is the finding that natural Rubisco kinetic diversity has evolved from amino acid differences outside of the catalytic pocket, sometimes in the distantly-located RbcS [12-14].

Defining what constitutes a better Rubisco is dependent on the cellular physiology of the target organism. In organisms incorporating a $\mathrm{CO}_{2}$-concentrating mechanism (CCM) to hinder Rubisco oxygenation (e.g., in most algae, cyanobacteria and plants with crassulacean acid metabolism, CAM, or C4-physiologies), improving the $\mathrm{CO}_{2}$ fixation rate $\left(k_{\text {cat }}{ }^{\mathrm{C}}\right)$ would represent a better Rubisco [1]. In organisms lacking a $\mathrm{CCM}$, such as $\mathrm{C}_{3}$ plants, the photosynthetic models show that improving Rubisco specificity for $\mathrm{CO}_{2}$ over $\mathrm{O}_{2}\left(\mathrm{~S}_{\mathrm{C} / \mathrm{O}}\right)$ and increasing carboxylation efficiency (i.e., $k_{\text {cat }}{ }^{\mathrm{C}}$ divided by the $\mathrm{K}_{\mathrm{m}}$ for $\mathrm{CO}_{2}$ under ambient $\mathrm{O}_{2}, \mathrm{~K}_{c}{ }^{21 \% \mathrm{O} 2}$ ) are key to producing a "better" Rubisco [15]. Rubisco from some red algae possesses these desired kinetic improvements. For example the $\mathrm{S}_{\mathrm{C} / \mathrm{O}}$ and $k_{\text {cat }}{ }^{\mathrm{C}} / \mathrm{K}_{c}{ }^{21 \% \mathrm{O} 2}$ values for red algae Griffithsia monilis Rubisco are, respectively, two-fold and 1.3-fold higher than tobacco Rubisco [16]. While this kinetic improvement has the potential to improve plant growth by $30 \%$ [17], the assembly requirements of red algae Rubisco are unfortunately not met in tobacco chloroplasts [18,19]. A comparable molecular chaperone incompatibility also impairs, or prevents, the assembly of heterologous plant and cyanobacteria Rubisco in tobacco chloroplasts [20-23].

A successful approach to improving Rubisco kinetics is via the directed evolution of randomly mutated $r b c L(+/-r b c S)$ libraries using high-throughput Rubisco-dependent Escherichia coli (RDE) screens $[22,24,25]$. As summarized in Figure 1, a core requirement shared among RDE screens is the expression of a prk gene coding phosphoribulose kinase (PRK). PRK catalyses the ATP-dependent phosphorylation of the ribulose 5-phosphate produced in the E. coli pentose phosphate pathway into RuBP. For unknown reasons, the PRK reaction is toxic to many E. coli strains unless Rubisco is introduced to catalyze the RuBP. As RDE selection is undertaken under elevated $\mathrm{CO}_{2}$, the RuBP is primarily carboxylated by Rubisco to produce the glycolytic intermediate 3PGA. Any 2PG produced via Rubisco oxygenase activity can also be metabolized by E. coli [26].

The life-death dependency of RDE screens on Rubisco activity has been exploited using the L-arabinose inducible $\mathrm{P}_{\mathrm{BAD}}$ promoter to modulate PRK expression (i.e., RuBP production) to select for cells producing higher levels of Rubisco activity. This improvement to RDE fitness can stem from mutations in Rubisco that either improve its biogenesis (i.e., increasing the solubility of Rubisco) or/and increase its catalytic rate. Failure to accurately determine which of these Rubisco biochemical properties improves RDE selection fitness has led to solubility-enhancing RbcL substitutions being erroneously reported as mutations that enhance carboxylase activity (Table 1) [25]. 
(a)

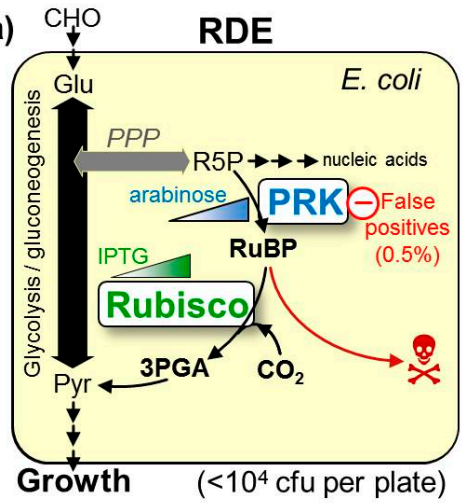

(b)

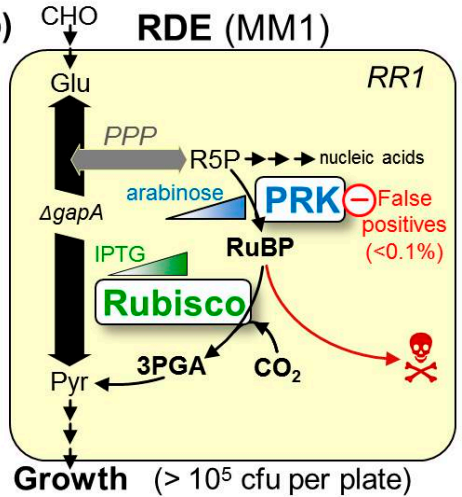

(c)

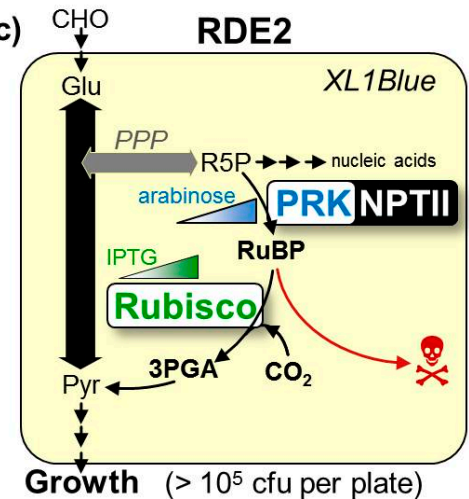

Figure 1. Metabolic rewiring in the different Rubisco dependent E. coli (RDE) screens. All RDE screens contain arabinose inducible BAD promoter-regulated prk genes whose product, phosphoribulokinase (PRK), phosphorylates ribulose 5-phosphate (R5P, produced in the pentose phosphate pathway, PPP) into RuBP. The toxicity of this reaction can be alleviated by expressing Rubisco to catalyse RuBP carboxylation into metabolically compatible 3-phosphoglycerate (3PGA). Cell growth can also arise from mutations that silence PRK to produce false positives (in which colony growth is independent of Rubisco activity). (a) The frequency of false positives in wild-type E. coli RDE screens is high $(\sim 0.5 \%$ of plated cells, left panel) reducing the number of colony-forming units (cfu) that can be effectively screened per plate. (b) The false positives frequency is $>5$-fold lower in the MM1 RDE system (middle panel) in which the gapA gene is deleted to stop flux through the glycolysis pathway [24]. (c) In RDE2, expressing PRK as an neomycin phoshotransferase II (NPTII) fusion prevents false positive selection, as silencing PRK co-suppresses NPTII expression, resulting in kanamycin sensitivity [22].

Table 1. Influence of commonly selected cyanobacteria Rubisco mutants on Rubisco content and catalysis (relative to wild-type, WT)—deciphering the trait that improves fitness.

\begin{tabular}{|c|c|c|c|c|c|c|c|c|c|c|}
\hline Amino Acid Mutation & $\begin{array}{l}{ }^{a} \text { Trait } \\
\text { Selected }\end{array}$ & $\begin{array}{c}\text { Rubisco } \\
\text { (Solubility) }\end{array}$ & $k_{\text {cat }}{ }^{\mathrm{C}}$ & $K_{C}$ & $K_{C}^{a i r}$ & $k_{\text {cat }}{ }^{\mathrm{C}} / \mathrm{K}_{\mathrm{C}}$ & \multicolumn{2}{|c|}{$k_{c a t}{ }^{C} / K_{C}{ }^{a i r} S_{C / O}$} & $\begin{array}{c}{ }^{\mathrm{b}} \text { Selection } \\
\text { Host }\end{array}$ & Reference \\
\hline \multicolumn{11}{|c|}{ SeRubisco (Synechococcus sp. PCC 6301)—Expressed in E. coli at $\sim 1 \%(w / w)$ of the Cell Soluble Protein. } \\
\hline \multirow{2}{*}{ F140I } & \multirow[t]{2}{*}{ solubility } & ${ }^{\mathrm{c}} \mathrm{WT}$ & $\begin{array}{c}c \uparrow \\
46 \%\end{array}$ & $\downarrow 48 \%$ & - & $\uparrow \mathbf{2 8 8} \%$ & - & $\downarrow 9 \%$ & MM1 & [27] \\
\hline & & $\uparrow 4.9$-fold & $\downarrow 12 \%$ & - & $\downarrow 16 \%$ & - & $\uparrow 6 \%$ & WT & RDE2 & [22] \\
\hline \multirow{3}{*}{ V189I } & \multirow{3}{*}{${ }^{d}$ solubility } & WT & $\uparrow 8 \%$ & $\downarrow 35 \%$ & - & $\uparrow 71 \%$ & - & $\downarrow 12 \%$ & MM1 & [27] \\
\hline & & $\uparrow 4.8$-fold & $\downarrow 16 \%$ & - & $\downarrow 26 \%$ & - & $\uparrow 14 \%$ & $\downarrow 15 \%$ & RDE2 & [22] \\
\hline & & - & $\downarrow 25 \%$ & $\downarrow 44 \%$ & $\downarrow 41 \%$ & $\uparrow 32 \%$ & $\uparrow 8 \%$ & - & R. capsulatus & [28] \\
\hline \multirow{3}{*}{ M262T } & \multirow{3}{*}{ d solubility } & $\uparrow$ 6-fold & $\uparrow 13 \%$ & $\downarrow 13 \%$ & - & $\uparrow 29 \%$ & - & WT & $\operatorname{RDE}(\mathrm{K} 12)$ & [29] \\
\hline & & $\uparrow$ 4-fold & - & - & - & - & - & - & MM1 & [22] \\
\hline & & - & WT & $\downarrow 23 \%$ & $\downarrow 15 \%$ & $\uparrow 23 \%$ & $\uparrow 18 \%$ & - & R. capsulatus & [28] \\
\hline \multirow{3}{*}{ F345I } & \multirow{3}{*}{ solubility } & $\uparrow$ 8-fold & $\downarrow 14 \%$ & $\uparrow 4 \%$ & $\uparrow 10 \%$ & $\downarrow 17 \%$ & $\downarrow 22 \%$ & $\downarrow 13 \%$ & MM1 & [30] \\
\hline & & $\uparrow$ 6-fold & $\downarrow 15 \%$ & $\uparrow 10 \%$ & - & $\downarrow 21 \%$ & - & $\downarrow 7 \%$ & MM1 & [27] \\
\hline & & $\uparrow$ 11.1-fold & $\downarrow 16 \%$ & - & $\uparrow 13 \%$ & - & $\downarrow 28 \%$ & $\downarrow 8 \%$ & RDE2 & [22] \\
\hline F345L & solubility & $\uparrow 7$-fold & $\downarrow 17 \%$ & $\uparrow 22 \%$ & - & $\downarrow 32 \%$ & - & $\downarrow 4 \%$ & MM1 & [30] \\
\hline F345V & solubility & - & $\downarrow 25 \%$ & $\uparrow 38 \%$ & - & $\downarrow 45 \%$ & - & $\downarrow 45 \%$ & R. capsulatus & [31] \\
\hline \multicolumn{11}{|c|}{ Te-Rubisco (Thermosynechococcus elongatus BP-1)—Expressed in E. coli at $\sim 6 \%(w / w)$ of the Soluble Protein. } \\
\hline F345I & solubility & $\uparrow 2.2$-fold & $\downarrow 27 \%$ & - & WT & - & $\downarrow 24 \%$ & $\downarrow 10 \%$ & RDE2 & [22] \\
\hline P415A & solubility & $\uparrow 1.6$-fold & $\uparrow 5 \%$ & - & WT & - & WT & WT & RDE2 & [22] \\
\hline P415A & $\begin{array}{c}\text { solubility/ } \\
\text { kinetic }\end{array}$ & $\uparrow 2.7$-fold & $\downarrow 27 \%$ & - & WT & - & $\downarrow 24 \%$ & $\downarrow 8 \%$ & RDE2 & [22] \\
\hline $\mathrm{V} 98 \mathrm{M}^{\mathrm{S}}$ & $\begin{array}{c}\text { solubility/ } \\
\text { kinetic }\end{array}$ & $\uparrow$ 3.1-fold & $\uparrow 44 \%$ & - & $\downarrow 13 \%$ & - & $\uparrow 44 \%$ & $\uparrow 6 \%$ & RDE2 & [22] \\
\hline
\end{tabular}


Table 1. Cont.

\begin{tabular}{|c|c|c|c|c|c|c|c|c|c|c|c|}
\hline \multicolumn{2}{|c|}{ Amino Acid Mutation } & \multirow{2}{*}{$\begin{array}{c}{ }^{a} \text { Trait } \\
\text { Selected }\end{array}$} & \multirow{2}{*}{$\begin{array}{c}\begin{array}{c}\text { Rubisco } \\
\text { (Solubility) }\end{array} \\
\uparrow 1.5 \text {-fold } \\
\end{array}$} & \multirow{2}{*}{$\begin{array}{l}k_{\text {cat }}{ }^{C} \\
\uparrow 33 \%\end{array}$} & \multirow{2}{*}{$\frac{K_{C}}{-}$} & \multirow{2}{*}{$\frac{K_{C}{ }^{a i r}}{\text { WT }}$} & \multirow{2}{*}{$\frac{k_{c a t}{ }^{C} / K_{C}}{-}$} & \multicolumn{2}{|c|}{$k_{c a t}{ }^{C} / K_{C}{ }^{a i r} S_{C / O}$} & \multirow{2}{*}{$\begin{array}{c}\begin{array}{c}\text { b Selection } \\
\text { Host }\end{array} \\
\text { RDE2 }\end{array}$} & \multirow{2}{*}{$\begin{array}{c}\text { Reference } \\
{[22]}\end{array}$} \\
\hline P415A & $\mathrm{A} 48 \mathrm{~V}^{\mathrm{S}}$ & & & & & & & $\uparrow 35 \%$ & $\downarrow 10 \%$ & & \\
\hline P415A & $\mathrm{H} 37 \mathrm{~L}^{\mathrm{S}}$ & kinetic & $\uparrow 1.7$-fold & $\uparrow 27 \%$ & - & WT & - & $\uparrow 28 \%$ & $\downarrow 7 \%$ & RDE2 & [22] \\
\hline P415A & $\mathrm{Y} 36 \mathrm{~N}^{\mathrm{S}} / \mathrm{G} 112 \mathrm{D}^{\mathrm{S}}$ & kinetic & $\uparrow 1.5$-fold & $\uparrow 41 \%$ & - & $\downarrow 12 \%$ & - & $\uparrow 60 \%$ & $\downarrow 10 \%$ & RDE2 & [22] \\
\hline P415A & L74M/D397N & $\begin{array}{l}\text { solubility/ } \\
\text { kinetic }\end{array}$ & $\uparrow 1.9$-fold & $\uparrow 24 \%$ & - & $\downarrow 14 \%$ & - & $\uparrow 45 \%$ & $=\mathrm{WT}$ & RDE2 & [22] \\
\hline
\end{tabular}

Amino acid numbering relative to plant RbcL (Figure A1). Data summarized from the Rubisco content and kinetic listings in Table A1. ${ }^{a}$ The governing biochemical feature that improves RDE fitness (i.e., cell growth rate). ${ }^{\mathrm{b}}$ A directed evolution screen is used to isolate the mutant (see Figure 1). The R. capsulatus screen is a low transformation frequency system that uses a Rubisco null mutant [31]. ${ }^{c}$ Underestimates of Rubisco content likely explain the erroneous carboxylation rate and efficiency improvements. ${ }^{d}$ Improvements in carboxylase properties may contribute to the improved fitness that is primarily imparted by the $>4$-fold increases in Rubisco biogenesis (solubility). Enhanced carboxylase activities are shown in bold-type. Arrows indicate whether the kinetic value is higher $(\uparrow)$ or lower $(\downarrow)$.

The common Rubisco substrate used in directed evolution studies is that from the cyanobacterium Synchococcus elongatus PCC6301 (SeRubisco, Table 1). When expressed in E. coli, the SeRubisco RbcL and $\mathrm{RbcS}$ are produced in high abundance, with $>90 \%$ of the RbcL produced forming misfolded insoluble aggregates, thereby limiting SeRubisco expression to $\sim 1 \%(w / w)$ of the soluble cellular protein $[27,29,30,32]$. Unassembled RbcS are less prone to insoluble aggregate formation, allowing them to rapidly bind (within $<1 \mathrm{sec}$ ) to $\mathrm{rbcL}_{8}$ cores to form stable $\mathrm{RbcL}_{8} \mathrm{RbcS}_{8}\left(\mathrm{~L}_{8} \mathrm{~S}_{8}\right)$ complexes [33]. The limitations to GroELS chaperonin facilitating Se-RbcL folding and assembly in $E$. coli have led to the repeated selection of particular amino acids changes (e.g., RbcL residues 140, 189, 262, 345; Figure A1) that improve SeRubisco biogenesis by $>4$-fold (Table 1 ). The impact of these mutations on catalysis is that they mostly impair-or at best provide only modest changes in—the carboxylation properties SeRubisco.

A recent, two-tiered directed evolution study used Te-Rubisco from Thermosynecococcus elongatus whose assembly requirements are better met in E. coli (produced at $\sim 6 \%(w / w)$ of the soluble cellular protein [22]). Using the "false-positive free" RDE2 screen (Figure 1), Te-Rubisco was evolved in sequential stages, with the first identifying the catalytically neutral P415A mutation that improved Te-Rubisco assembly 1.6-fold. The second cycle of evolution then successfully selected additional mutations to P415A that were all co-located at the RbcL-RbcS interface of the holoenzyme that could enhance $k_{c a t}{ }^{C}, k_{c a t}{ }^{C} / K_{c}{ }^{21 \% O 2}$ and $S_{C / O}$ (Table 1 ).

In this study, we trial a re-designed version of the RDE2 screen (here, named RDE3) to evolve Form I RsRubisco from Rhodobacter sphaeroides. Unlike SeRubisco and plant Rubisco (that are both in the "green-type" Form IB lineage), RsRubisco is in the "red-type" Form IC lineage and more related to the catalytically superior Form ID algae Rubisco from G. monilis [34,35]. Unlike the RDE2 screen, RsRubisco production in the RDE3 system is regulated by bacteriophage T7 transcription and undertaken in JM109(DE3), a lacUV5-regulated T7 RNA polymerase-expressing E. coli strain sensitive to PRK expression. Described is a model-directed evolution experimental pipeline using RDE3 that distinguished amino acid substitutions that impair RsRubisco biogenesis from one that significantly enhanced $k_{\text {cat }}{ }^{\mathrm{C}}$ and $k_{\text {cat }}{ }^{\mathrm{C}} / \mathrm{K}_{\mathrm{C}}$.

\section{Results}

\subsection{Ambiguity in How Cyanobacteria Rubisco Mutations Improve RDE Fitness}

Prior RDE-directed evolution studies have mistakenly reported SeRbcL amino acid substitutions which improve the folding and assembly (solubility) of SeRubisco as mutations that enhance catalysis. As summarized in Table 1, the commonly selected M262T SeRbcL substitution initially reported to enhance catalysis [36] was subsequently shown to enhance SeRubisco solubility in E. coli [29] and may also account for the same mutation enhancing fitness in R. capsulatus selection [28]. Similarly the 
SeRbcL F140L and V189I mutations were initially characterized a catalytic enhancers of RDE fitness [27] but subsequently shown to improve SeRubisco solubility by nearly 5-fold in E. coli [22].

The erroneous assessment of $\mathrm{L}_{8} \mathrm{~S}_{8}$ recombinant holoenzyme production in E. coli often stems from the inherent complexity of the enzyme assembly requirements that impair its synthesis in heterologous hosts $[24,25,37]$. This is particularly true for the cyanobacteria Rubisco, whose assembly requirements are either not met, or are poorly met, in E. coli $[29,32]$. For example, the SeRbcL and SeRbcS subunits are produced in abundance in E. coli, with SeRbcL comprising $>10 \%(w / w)$ of the total cellular protein (Figure 2a). Compared to SeRbcS that is mostly soluble, more than $90 \%$ of the SeRbcL produced in E. coli forms misassembled insoluble protein aggregates (compare the lysate and soluble SeRbcL and SeRbcS immunoblot signals in Figure 2b). The remaining soluble SeRbcL are primarily found assembled in $\mathrm{Se}_{8} \mathrm{~S}_{8}$ complexes, with the unassembled soluble SeRbcS monomers able to bind instantaneously with any assembled $\mathrm{RbcL}_{8}$ cores via a chaperone-independent process [33]. By comparison, the assembly requirements of RsRubisco are more readily met in E. coli, with a greater proportion of soluble RsRbcL produced and assembled into $R_{s} \mathrm{~L}_{8} \mathrm{~S}_{8}$ complexes (Figure 2c).
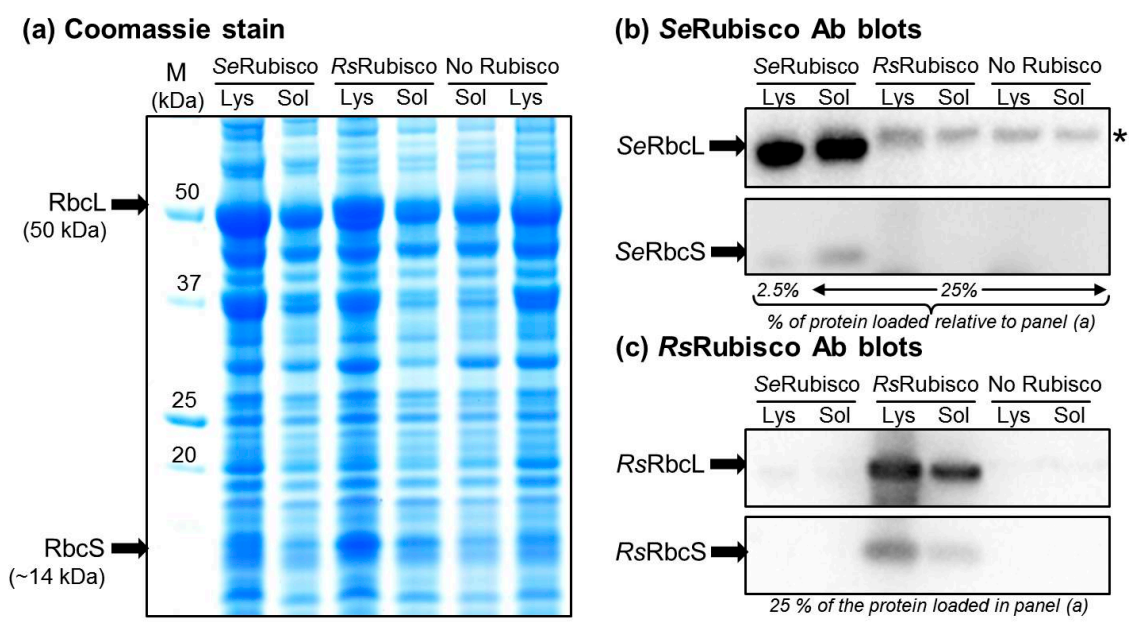

Figure 2. SDS PAGE analysis of SeRubisco and RsRubisco production in BL21(DE3). Rubisco production was induced at $25{ }^{\circ} \mathrm{C}$ with $0.5 \mathrm{mM}$ isopropyl- $\beta$-D-thiogalactosidase (IPTG) for $8 \mathrm{~h}$, the cells were lysed and (a) $4 \mu \mathrm{g}$ of soluble protein ( $\mathrm{Sol}$ ) and an equivalent volume of the total cellular protein (Lys, comprising soluble, membrane and insoluble inclusion body proteins) were separated by SDS PAGE and Coomassie stained. Duplicate PAGE gels loaded with lower amounts of each protein preparation (as indicated) were blotted onto nitrocellulose membranes and probed with antibodies (Ab) to (b) SeRubisco and (c) RsRubisco. Empty vector BL21(DE3)-pET28a(+) cells were used as a "no Rubisco" control. *, E. coli protein recognized by the SeRubisco antibody. The SeRbcL is produced in high abundance and mostly insoluble (lysate signal >> soluble signal), while SeRbcS, RsRbcL and $R s R b c S$ are mostly soluble. SeRubisco and RsRubisco $\mathrm{L}_{8} \mathrm{~S}_{8}$ contents comprised, respectively, $1.1 \%$ and $4.8 \%(w / w)$ of the soluble cellular protein (as quantified by ${ }^{14} \mathrm{C}$ - carboxyarabinitol 1,5-bisphospahte (CABP)-binding). $\mathrm{M}$, protein markers (sizes shown).

The low level of SeRubisco produced in E. coli (comprising 1\% $(w / w)$ of the E. coli-soluble protein, Table 1) hinders the viability of SDS PAGE, Western blotting and native PAGE methods to quantify Rubisco content. Even when analyzed alongside known amounts of SeRubisco, these methods can lack sufficient quantifiable resolution [38]. By contrast, the tight and stoichiometric binding properties of the Rubisco specific inhibitor carboxyarabinitol 1,5-bisphospahte (CABP) provide an accurate method to quantify Rubisco in any soluble cellular protein sample [39]. The method, termed ${ }^{14} \mathrm{C}-\mathrm{CABP}$ binding, takes advantage of CABP's capacity to tightly bind to each Rubisco catalytic site to form a highly stable complex that, upon separation from unbound ${ }^{14} \mathrm{C}-\mathrm{CABP}$ (e.g., by gel filtration), provides an accurate quantitative measure of Rubisco content [38]. 


\subsection{An Analytical Pathway for the Directed Evolution of Rubisco Using an RDE Screen}

Our routine Rubisco-directed evolution experimental protocol spanning RDE selection to in vitro biochemistry analytics is summarized in Figure 3 [22,40]. The experimental pipeline begins with the generation and transformation of an $r b c L(+/-r b c S)$ mutant library into an RDE screen alongside RDE cells expressing the non-mutated $r b c l-r b c s$ gene control (Figure 3a). Colonies showing improved RDE fitness (i.e., those which can grow on PRK-inducing arabinose and IPTG-inducing Rubisco concentrations that have been pre-determined to be non-permissive to the growth of cells expressing the parental Rubisco substrate) are individually selected, and the $r b c l-r b c s$ plasmid is isolated, retransformed into RDE and the colony growth on increasing arabinose compared with the control cells to gauge the relative improvement in cell "fitness" (Figure 3b). The $r b c l-r b c s$ plasmid is isolated and sequenced from the RDE cells with improved fitness and transformed into a suitable E. coli strain to quantify changes in Rubisco expression and catalysis (Figure 3c). SDS PAGE samples of the total and soluble cell protein are taken to qualitatively assess the proportion of soluble and insoluble RbcL and $\mathrm{RbcS}$ produced (Figure 2). The soluble protein concentration is measured, the Rubisco content is quantified by ${ }^{14} \mathrm{C}-\mathrm{CABP}$ binding, and 4 to $8 \mu \mathrm{g}$ of protein is separated by native PAGE to verify the $\mathrm{L}_{8} \mathrm{~S}_{8}$ Rubisco content and aliquots used in ${ }^{14} \mathrm{CO}_{2}$-fixation assays to quantify the $\mathrm{CO}_{2}$-fixation rate $\left(k_{\text {cat }}{ }^{\mathrm{C}}\right)$ and the $\mathrm{K}_{\mathrm{m}}$ for $\mathrm{CO}_{2}$ under anaerobic conditions $(\mathrm{Kc})$, ambient $\mathrm{O}_{2}$ levels $\left(\mathrm{K}_{\mathrm{C}}{ }^{21 \% \mathrm{O} 2}\right)$, or over a range of $\mathrm{O}_{2}$ levels to quantify the $\mathrm{K}_{\mathrm{m}}$ for $\mathrm{O}_{2}\left(K_{O}\right)$ [22]. To accurately measure the specificity for $\mathrm{CO}_{2}$ over $\mathrm{O}_{2}$ $\left(\mathrm{S}_{\mathrm{C} / \mathrm{O}}\right)$, the method of Kane et al. (1994) [41] is used, which requires Rubisco that has been purified from the E. coli using a rapid ion exchange and gel filtration process [42].
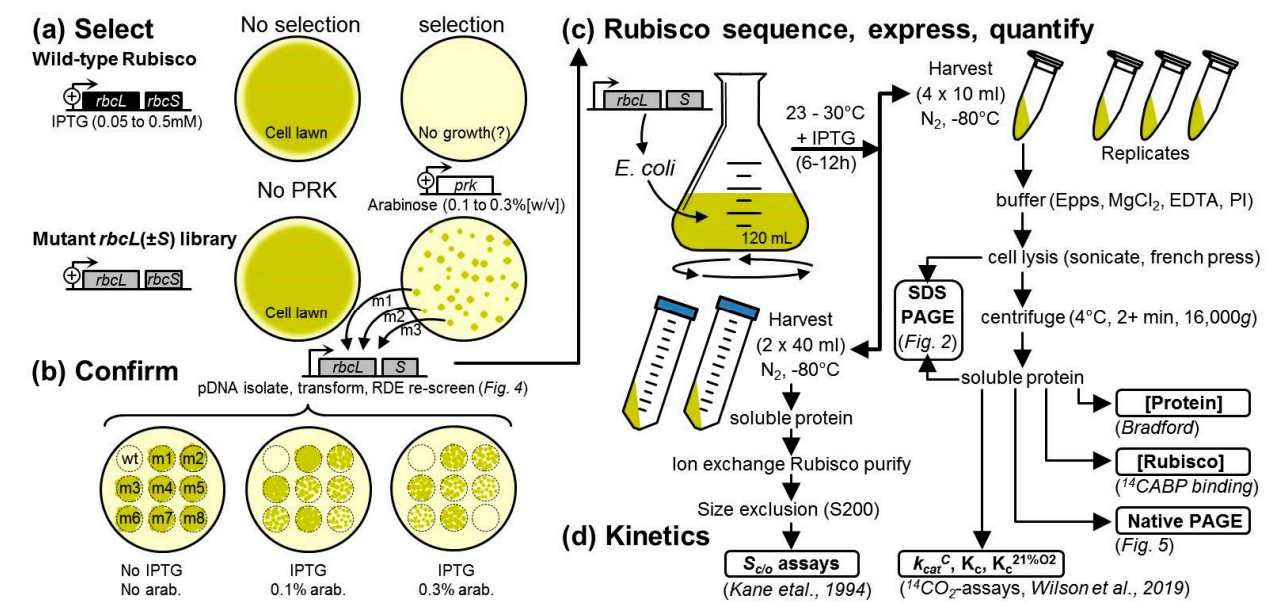

Figure 3. The analytical pipeline of an RDE experiment. An RDE-directed evolution project begins with (a) Rubisco gene library generation, transformation and RDE selection. The Rubisco gene plasmid $(r b c l-r b c s)$ from cells with improved fitness is (b) transformed into fresh RDE cells and re-screened on PRK-inducing arabinose to confirm the improved growth phenotype before (c) sequencing to ascertain the amino acid substitutions. Each Rubisco mutant is then expressed in E. coli and the Rubisco subunit folding/assembly capacity evaluated by SDS PAGE (e.g., Figure 2); the $\mathrm{L}_{8} \mathrm{~S}_{8}$ holoenzyme content is then quantified $\left({ }^{14} \mathrm{C}-\mathrm{CABP}\right.$ binding), confirmed (native PAGE) and (d) the kinetics $\left(\mathrm{S}_{\mathrm{C} / \mathrm{O}}, \mathrm{k}_{\mathrm{cat}}{ }^{\mathrm{C}}, \mathrm{K}_{\mathrm{C}}\right.$ and $\mathrm{K}_{\mathrm{C}}{ }^{21 \% \mathrm{O} 2}$ ) measured as described in [22].

\subsection{Determination of a Suitable E. coli Strain for RDE3}

As in any directed protein evolution experiment, the level of success is dependent on the fidelity and throughput of the selection system employed. For evolving Rubisco, the use of the photosynthetic R. capsulitis bacterial screen is hampered by low throughput (screening is limited to a few thousand mutants) and hindered in its ability to characterize mutants with alterations in solubility [28,31,43,44]. As summarized in Figure 1, while RDE screens have higher throughput, their fidelity can be compromised by false positives. These occur at a higher frequency $(\sim 0.5 \%$ of 
the colony forming units plated) in the original RDE screens than in the metabolically altered MM1 RDE strain [24]. The false positives produced in MM1 selection have primarily been attributed to transposon insertions into a pACYCRPK plasmid that silenced PRK production [25]. This has been avoided in the RDE2 screen by fusing NPTII onto the PRK C-terminus and including kanamycin in the selection media, meaning that false positives originating from transposon-induced PRK silencing cannot grow (Figure 1) [22].

In this study, we sought to adapt the RDE2 screen so that Rubisco production was regulated by bacteriophage T7 transcription rather than the previously used lac promoter in pTrcHisB. This necessitated that RDE selection be undertaken in a lacUV5-regulated T7 RNA polymerase-expressing E. coli strain. The plating of differing E. coli strains transformed with $\mathrm{PACYC}{ }^{\text {prk:kan }}$ on media containing differing arabinose concentrations found differences in their susceptibility to PRK-NPTII production (Figure 4). The JM109(DE3), XL1-Blue and DH5 $\alpha$ strains were sensitive to PRK-NPTII synthesis, while DB3.1, BL21(DE3) and BW25113 were not, making the latter three strains unsuitable for use in an RDE screen. The pACYC ${ }^{\text {prk:kan }}$ plasmids from DB3.1, BL21(DE3) and BW25113 colonies growing on $0.25 \%(w / v)$ arabinose were purified, restriction digested (Figure A2) and sequenced. There was no evidence that PRK-NPTII production was compromised, indicating that these three strains show an insensitivity to PRK production under the growth conditions trialed.

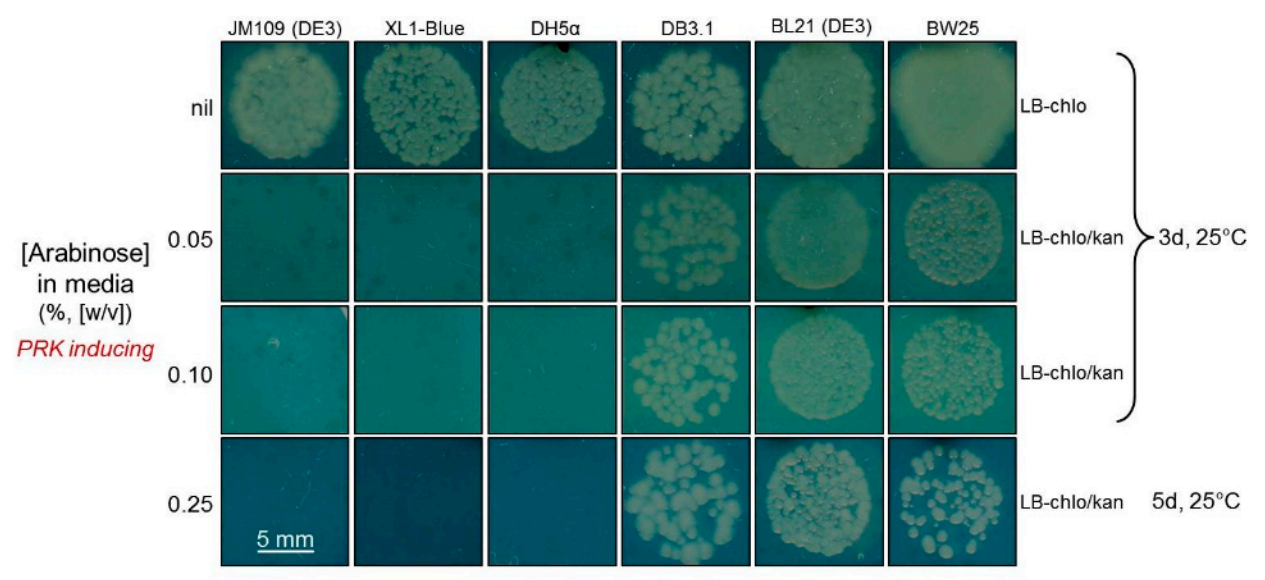

Figure 4. Comparative growth of differing E. coli strains under increasing PRK-NPTII expression. Six E. coli strains were transformed with pACYC ${ }^{\text {rrk:kan }}$ and grown on LB-medium containing four different arabinose concentrations. Chloramphenicol (chlo, $30 \mu \mathrm{g} / \mathrm{mL}^{-1}$ ) and kanamycin (kan, $125 \mathrm{\mu g} / \mathrm{mL}^{-1}$ ) were included in the LB plates, as indicated.

As JM109(DE3) is suited to T7-regulated recombinant expression, it was the strain used in our new RDE3 screen. Comparative expression analyses found that RsRubisco was expressed equally well in JM109(DE3) $(\sim 5 \%(w / w)$ of the soluble protein, see Table 2$)$ as in BL21(DE3) (Figure 2).

\subsection{Directed Evolution of RsRubisco in the RDE3 Screen}

In this pilot RDE3-directed evolution experiment, the Form IC RsRubisco was the chosen substrate as (1) its assembly requirements are well met in E. coli (Figure 2) including in JM109(DE3) (Table 2), (2) it is of the "red-type" Rubisco phylogenetic lineage that encompasses the superior Form ID Rubisco isoforms from red algae [35], and (3) it has not been used in a directed evolution study. Electro-competent JM109(DE3) containing pACYC ${ }^{\text {rk:kan }}$ [22] (here on termed RDE3 cells) were transformed with an Rs-rbcl-rbcs mutant library cloned into plasmid pYZRsLS (Amp ${ }^{\mathrm{R}}$, Figure 5a). Approximately $10^{5}$ colony forming units (cfu) were plated on a $150 \mathrm{~mm}$ plate of selective LB media containing $75 \mu \mathrm{M}$ IPTG, $0.25 \%(w / v)$ arabinose and antibiotics (Figure $5 \mathrm{~b}$ ). RDE3-pYZRsLS cells expressing non-mutated RsRubisco $\left(2 \times 10^{4} \mathrm{cfu}\right.$; wild-type (WT) control) were grown on a $90 \mathrm{~mm}$ plate of replica selection media. After five days at $25^{\circ} \mathrm{C}$ in air supplemented with $2 \%(v / v) \mathrm{CO}_{2}, 37$ colonies had grown on the mutant RsRubisco plate and eight on the WT RsRubisco control (Figure $5 \mathrm{~b}$ ). 
The pYZRsLS from 33 mutant and all eight WT colonies were purified and restriction-digested to confirm they contained the Rs-rbcLS operon before re-transforming into fresh RDE3 cells and plating again onto LB containing $0.25 \%(w / v)$ arabinose (Figure $5 c$ ). Only one mutant, called YZ1, enhanced the growth fitness of RDE3 under this selection pressure, with the remainder showing comparable arabinose sensitivities to the pYZRsLS(WT) control (Figure 5c).

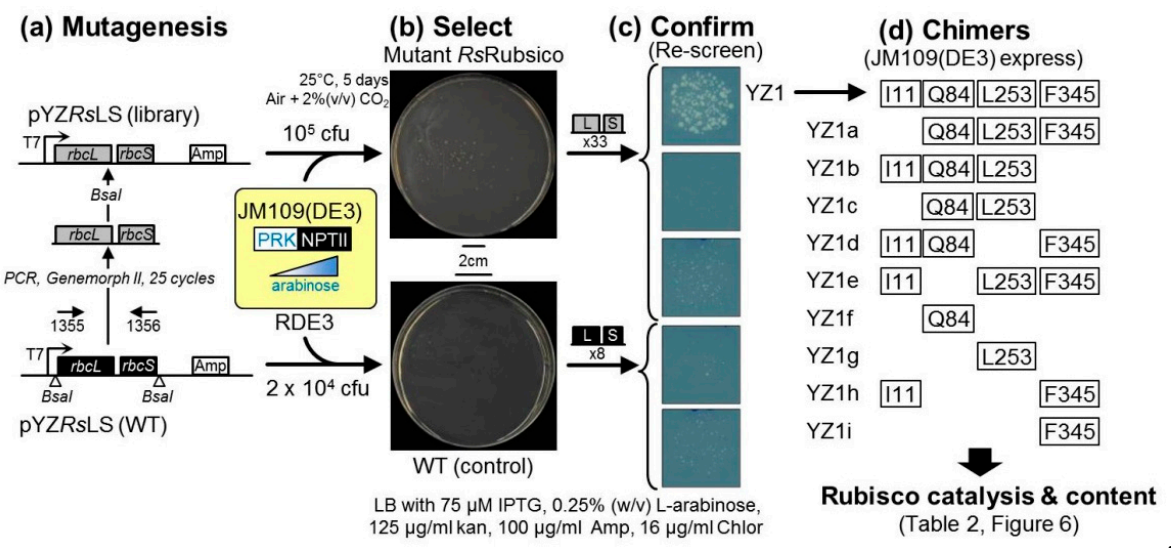

Figure 5. RDE3 evolution of RsRubisco. (a) Wild-type (WT) and a mutated Rs-rbcLS operon library cloned into pYZRsLS were transformed into RDE3 and (b) screened under strong arabinose selection as shown. The surviving colonies were grown (under non-selective conditions), the pYZRsLS purified and those containing the Rs-rbcLS operon re-transformed into RDE3 and (c) re-grown on selection media (examples for five of the 41 RDE3 re-screens are shown). Only the YZ1 mutant improved RDE3 growth, and (d) the sequencing of its Rs-rbcLS operon showed that it coded RbcL mutations V11L, K84Q, R253L and Y345F (plant RbcL numbering, Table A1). Nine YZ1 chimers (named YZ1a to YZ1i) coding differing combinations of these mutations were created to study how they influence RsRubisco biogenesis (Figure 6) and catalysis (Table 2).

Table 2. Comparative E. coli biogenesis (solubility) and catalysis (at $25^{\circ} \mathrm{C}$ ) of wild-type, $\mathrm{YZ} 1$ and their RsRubisco chimers.

\begin{tabular}{|c|c|c|c|c|c|c|c|c|c|c|c|c|}
\hline \multirow{2}{*}{ RsRubisco Isoform } & \multicolumn{4}{|c|}{ RbcL Residue Number } & \multirow{2}{*}{$\begin{array}{c}\text { Rubisco } \\
\text { a (\% CSP) }\end{array}$} & \multirow{2}{*}{$\begin{array}{c}K_{C} \\
(\mu \mathrm{M})\end{array}$} & \multirow{2}{*}{$\begin{array}{l}k_{\text {cat }}{ }^{-} \\
\left(\mathrm{s}^{-1}\right)\end{array}$} & \multirow{2}{*}{$\begin{array}{l}K_{\text {cat }}{ }^{C} / K_{C} \\
\left(\mathrm{mM}^{-1} \mathrm{~s}^{-1}\right)\end{array}$} & \multirow{2}{*}{ 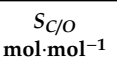 } & \multirow{2}{*}{$\begin{array}{c}K_{O} \\
(\mu \mathrm{M})\end{array}$} & \multirow{2}{*}{$\begin{array}{c}k_{\text {cat }}{ }^{O} \\
\left(\mathrm{~s}^{-1}\right)\end{array}$} & \multirow{2}{*}{$\begin{array}{l}k_{\text {cat }}{ }^{O} / K_{O} \\
\left(\mathrm{mM} \cdot \mathrm{s}^{-1}\right)\end{array}$} \\
\hline & 11 & 83 & 252 & 345 & & & & & & & & \\
\hline WT & Val & Lys & $\operatorname{Arg}$ & Tyr & $4.9 \pm 0.4^{\mathrm{a}}$ & $60 \pm 1^{a}$ & $3.7 \pm 0.2^{\mathrm{a}}$ & $60 \pm 1$ & $58 \pm 1^{a}$ & $1724 \pm 280$ & 1.8 & 1.0 \\
\hline YZ1 & Ile & Gln & Leu & Phe & $2.9 \pm 0.1^{b}$ & $66 \pm 1^{a}$ & $4.7 \pm 0.1^{c}$ & $70 \pm 1$ & $57 \pm 1^{\mathrm{a}}$ & $1296 \pm 207$ & 1.6 & 1.3 \\
\hline YZ1b & Ile & Gln & Leu & Tyr & $3.0 \pm 0.1^{b}$ & $61 \pm 1^{\mathrm{a}}$ & $3.8 \pm 0.1^{\mathrm{a}}$ & $63 \pm 1$ & - & - & - & - \\
\hline YZ1c & Val & Gln & Leu & Tyr & $3.6 \pm 0 . a^{b}$ & $63 \pm 1^{a}$ & $3.9 \pm 0.1^{\mathrm{ab}}$ & $63 \pm 1$ & - & - & - & - \\
\hline YZ1d & Ile & Gln & Arg & Phe & $4.6 \pm 0.1^{a}$ & $62 \pm 1^{a}$ & $4.6 \pm 0.1^{c}$ & $76 \pm 1$ & - & - & - & - \\
\hline YZ1e & Ile & Lys & Leu & Phe & $4.5 \pm 0.3^{a}$ & $63 \pm 1^{a}$ & $4.3 \pm 0.1^{b c}$ & $70 \pm 3$ & - & - & - & - \\
\hline YZ1h & Ile & Lys & Arg & Phe & $4.6 \pm 0.1^{\mathrm{a}}$ & $61 \pm 1^{\mathrm{a}}$ & $4.4 \pm 0.1^{\mathrm{a}}$ & $73 \pm 1$ & - & - & - & - \\
\hline YZ1i & Val & Lys & Arg & Phe & $4.7 \pm 0.2^{a}$ & $64 \pm 1^{a}$ & $4.6 \pm 0.1^{a}$ & $71 \pm 2$ & $59 \pm 1^{a}$ & $1551 \pm 293$ & 1.9 & 1.2 \\
\hline
\end{tabular}

Values in bold represent significant improvements in carboxylase activity. CSP (percentage ( $w / w)$ of the cell soluble protein), $k_{\text {cat }}{ }^{\mathrm{C}}$ and $K_{\mathrm{C}}$ data are the mean $\pm \mathrm{SE}$ of $N=5$ (and for $\mathrm{S}_{\mathrm{C} / \mathrm{O}} N=2$ ) biological samples, each assayed in duplicate. Letters show the ranking of the means using a post hoc Tukey test (different letters indicate statistical differences at the $5 \%$ level, $p<0.05$ ) following a one-way ANOVA comparison relative to WT. $k_{c a t} \mathrm{O}$, maximal oxygenation rate, calculated from $S_{C / O}=\left(k_{c a t} C / K_{C}\right) /\left(k_{c a t}{ }^{C} / K_{O}\right)$. Mutated residues are shaded black.

\subsection{The RbcL Substitution Y345F Enhances RsRubisco Carboxylation without Impairing Enzyme Biogenesis}

The sequencing of the YZ1 pYZRsLS plasmid found it coded five Rs-rbcL nucleotide mutations, with four coding the RsRbcL mutations V11L (GTT-ATT), K85Q (AAA-CAA), R254L (CGT-CTT) and Y346F (TAT-TTT) and one a synonymous CTG-CTC change to L391. Relative to tobacco Rubisco, numbering these mutations corresponded to K83Q, R252L and Y345F (Figure A1a). A kinetic analysis of YZ1 RsRubisco found that the RbcL mutations had no effect on the $S_{C / O}$ but significantly stimulated $k_{\text {cat }}{ }^{C}$ and carboxylation efficiency $\left(k_{\text {cat }}{ }^{C} / K_{C}\right)$ by $27 \%$ and $17 \%$, respectively (Table 2 ). The mutations also increased the affinity of $\mathrm{YZ1-Rubisco}$ for $\mathrm{O}_{2}$ (i.e., $\mathrm{K}_{O}$ was $25 \%$ lower than $R s$ Rubisco), thereby 
reducing its $\mathrm{CO}_{2}$ affinity under ambient $\mathrm{O}_{2}\left(\mathrm{~K}_{\mathrm{C}}{ }^{21 \% O 2}=78.8 \mu \mathrm{M}\right)$ relative to wild-type RsRubisco $\left(K_{C}{ }^{21 \% O 2}=68.8 \mu \mathrm{M}\right)$. Nevertheless, the carboxylation efficiency of YZ1-Rubisco in air $\left(k_{\text {cat }}{ }^{C} / K_{C}{ }^{21 \% O 2}=\right.$ $\left.59.6 \mathrm{mM}^{-1} \cdot \mathrm{s}^{-1}\right)$ still exceeded RsRubisco $\left(53.8 \mathrm{mM}^{-1} \cdot \mathrm{s}^{-1}\right)$ by $11 \%$.

The analysis of YZ1-RsRubisco solubility by ${ }^{14} \mathrm{C}-\mathrm{CABP}$ binding and native PAGE showed its biogenesis in JM109(DE3) was $\sim 40 \%$ lower than wild-type RsRubisco (Table 2, Figure 6 ). A series of nine YZ1 RsRubisco chimers coding one to three RbcL amino acid substitutions was made (called YZ1a to $\mathrm{YZi}$, Figure $5 \mathrm{~d}$ ) to examine whether the changes in biogenesis and kinetics could be uncoupled. As summarized in Table 2, all YZ1-chimers incorporating the Y345F mutation sustained the kinetics of YZ1 RsRubisco, demonstrating that this mutation imparted the improved $k_{c a t}{ }^{C}$ and $k_{\text {cat }}{ }^{\mathrm{C}} / \mathrm{K}_{\mathrm{C}}$ kinetic phenotype. The assembly of RsRubisco was only impaired in the YZ1-chimers coding both K83Q and R252L together (YZ1, YZ1a, YZ1b, YZ1c, Table 2, Figure 6). On their own (YZ1f, Yz1g) or in combination (YZ1c), the K83Q and R252L substitutions had no significant influence on RsRubisco kinetics (Table 2). The separation of all the YZ1 RsRubisco chimers incorporating K83Q through native PAGE was marginally faster, suggesting that the mutation altered the net charge of the enzyme or induced a structural conformational change that increased its migration rate (Figure 6).

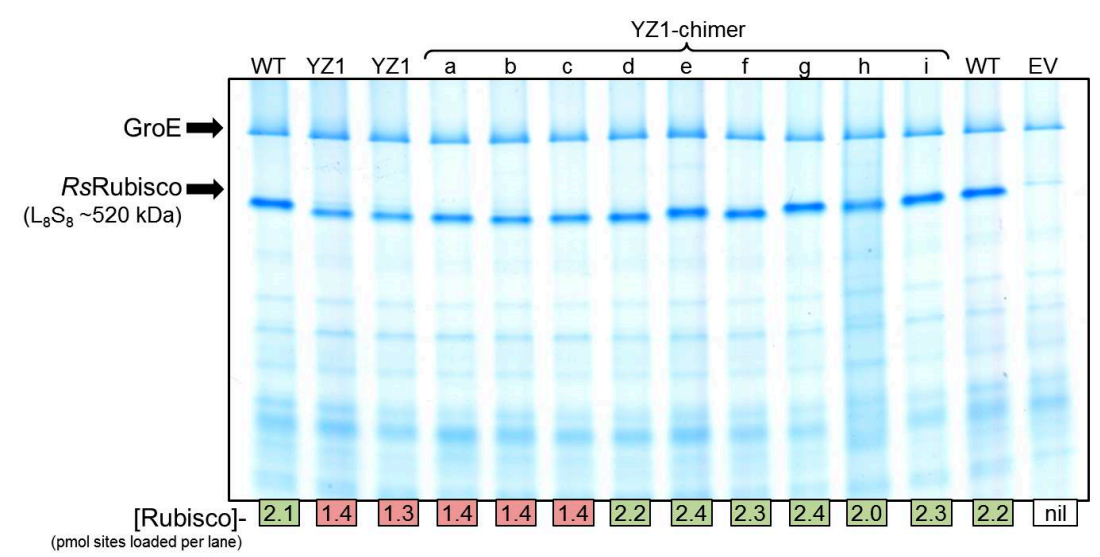

Figure 6. Native PAGE analysis of RsRubisco and the YZ1 chimers' relative expression in JM109(DE3) after $0.5 \mathrm{mM}$ IPTG induction for $6 \mathrm{~h}$ at $28^{\circ} \mathrm{C}$. The separated soluble cellular protein $(4 \mu \mathrm{g}$, including an empty vector (EV) JM109(DE3)-pET28a(+) control) was Coomassie stained, with the RsRubisco band intensity correlating with that quantified by ${ }^{14} \mathrm{C}-\mathrm{CABP}$ binding (indicated at base of gel). RsRubisco biogenesis for the YZ1 chimers similar to wild-type (WT) are shaded green, while those produced in amounts equivalent to YZ1-RsRubisco are shaded red.

\section{Discussion}

A common challenge encountered with Rubisco-directed evolution studies using RDE selection is accurately measuring the biochemical properties of the mutant enzymes to correctly interpret the basis of how they improved RDE fitness [25]. Inaccuracies primarily arise from the erroneous evaluation of how amino acid substitutions affect Rubisco assembly (solubility) and kinetics (Table 1). Here, we demonstrate an experimental pipeline that spans the "selection" to the "analysis" phases of RDE-directed evolution (Figure 3). Using the pipeline, we successfully identified amino acids in Form IC "red-type" RsRubisco that influence either solubility or catalysis (Table 2). Our success in improving the carboxylation properties of RsRubisco extends to the comparable achievements made using MM1 and RDE2 in identifying amino acid substitutions that improve the carboxylase activities of the archaeon Methanococcoides burtonii Form III Rubisco decamer ( $\mathrm{rbcL}_{10}$, [40]) and the Form IB “green-type" $\mathrm{L}_{8} \mathrm{~S}_{8}$ TeRubisco [22]. The chimeric dissection of the selected YZ1 RsRubisco mutant identified $\mathrm{Y} 345 \mathrm{~F}$ as a mutation that increases carboxylase activity and K84Q and R253L as substitutions that, in combination, impair $\mathrm{L}_{8} \mathrm{~S}_{8}$ biogenesis (Table 2). Our findings also show that sensitivity to PRK production varies between E. coli strains (Figure 4) and that RDE false positive selection can arise independently from $p r k$ silencing (Figure $5 b, c$ and Figure A2). This raises questions 
regarding the validity of the underpinning basis for RDE selection; i.e., that cell fitness is dependent on Rubisco expression to alleviate the inexplicable cellular toxicity of PRK-dependent RuBP production (Figure 1, [24]), a metabolic impediment that does not appear universal among all E. coli strains.

\subsection{Mutating RbcL Amino Acid 345 Has Alternate Effects on Form I Rubisco Biogenesis and Catalysis}

A common outcome of RDE screens is the selection of Rubisco mutants coding amino acid substitutions at residue 345 (numbered according to plant Rubisco, Table 1). Amino acid 345 is positioned in $\alpha$-helix 6 of the six-stranded $\alpha / \beta$-barrel C-domain of RbcL (as structurally defined by [45]). In the $\mathrm{L}_{8} \mathrm{~S}_{8}$ structure residue, 345 is embedded beneath the enzymes' outer surface, away from subunit interfaces and $~ 5.6 \AA$ from Arg-295, a conserved catalytic site residue involved in binding the $\mathrm{P} 5$ phosphate group of RuBP (Figure 7). Adjoining $\alpha$-helix 6 is the catalytic loop 6 (residues ${ }_{331}$ AVGKLE $_{336}$, Figure A1). This conserved, flexible, "lid-like" sequence interacts with the C-terminal tail to close over the catalytic pocket upon RuBP binding, then opening upon catalysis to allow product release [10]. Among Form IB and ID Rubisco isoforms, position 345 is phenylalanine (Phe, F), and in cyanobacteria Form IA Rubisco and RsRubisco Form IC, it is a tyrosine (Tyr, Y) (Figure A1). A mutagenic analysis of Form IB SeRubisco found changes to $\alpha$-helix 6 amino acids located closer to loop 6 dramatically impaired carboxylase activity [46]. Not included in this analysis were changes to the other $\alpha$-helix $6 \mathrm{G}^{345} \mathrm{FVDL}$ residues that are conserved among Form IB Rubisco. From this analysis, it was hypothesized that structural changes in $\alpha$-helix 6 can influence loop 6 positioning and movement [46]. Such movements are thought to alter how K334 (the catalytically critical loop 6 apex residue) ligands with the $\mathrm{RuBP}$ enediolate transition state intermediate and influences its catalysis with $\mathrm{CO}_{2}$ or $\mathrm{O}_{2}$.

(a) RbcL

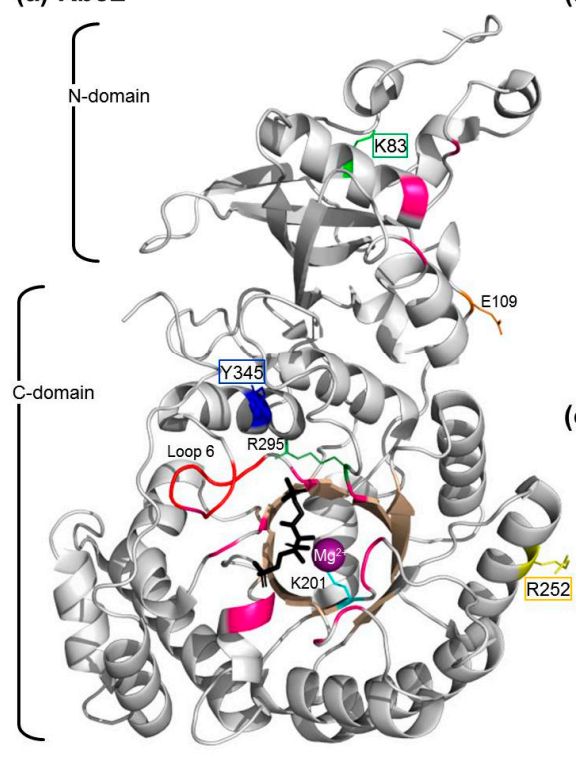

(b) $L_{8} S_{8}$

(c) $\mathrm{L}_{4} \mathrm{~S}_{2}$

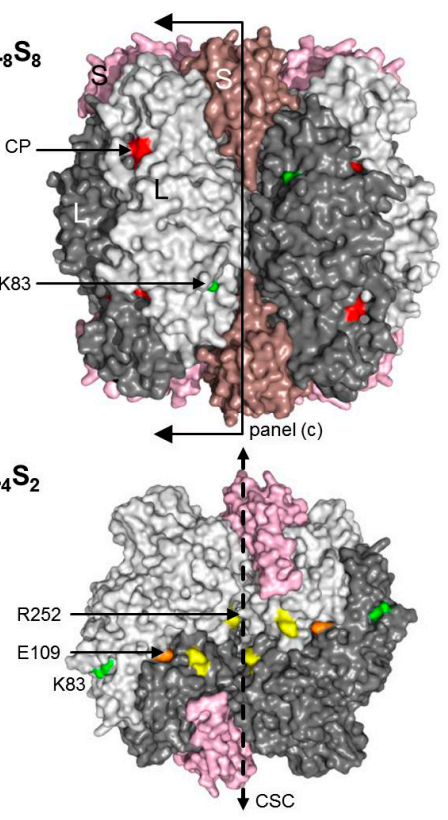

Figure 7. Mapping the location of the RDE3-selected YZ1 mutations in R. sphaeroides Rubisco. Pymol-assembled RsRubisco (PDB 5NV3) structures of (a) a single RsRbcL subunit, (b) $\mathrm{L}_{8} \mathrm{~S}_{8}$ holoenzyme (side view) and (c) $\mathrm{L}_{4} \mathrm{~S}_{2}$ sub-complex (cross-section view). RbcL pairs are colored with differing shades of grey, and RbcS is alternately colored pink/salmon. Shown are the locations of the YZ1-selected RbcL amino acid substitutions K83Q (green, strand C), R252L (yellow, $\alpha$-helix 3) and Y345F (blue, $\alpha$-helix 6) relative to the conserved catalytic pocket (CP) residues (dark pink), including R295 (green), K201 (light blue) loop 6 (red) and CABP (black, RuBP intermediary analog). E109 (orange) forms a salt bridge with a conserved R253 in the adjacent RbcL. The R252L substitution is located on the surface of the central solvent channel (CSC) that traverses the inner core of the $\mathrm{L}_{8} \mathrm{~S}_{8}$ holoenzyme (dashed arrow, panel c). Residues are numbered relative to plant Rubisco using the alignment in Figure A1. 
The existing data suggest that changes to residue 345 have a pervasive influence on Rubisco catalysis. For example, replacing Phe 345 with Ile, Leu or Val impairs the carboxylation properties of SeRubisco [27,30] and TeRubisco [22] (Table 1). It is difficult to structurally ascertain whether these kinetic changes arise from the mutations altering the positioning and movement of loop 6 or by altering RuBP ligand binding with Arg-295 in the catalytic pocket. Inexplicably, mutations to F345 also somehow impart two to 11-fold improvements in TeRubisco and SeRubisco production (Table 1). It is presumed that these changes enhance $S e R b c L$ and TeRbcL folding and/or assembly in E. coli [22,24,27]. By contrast, the Y345F substitution in RsRbcL had no effect on RsRubisco biogenesis in E. coli and improved its carboxylation rate and efficiency by 27 and $17 \%$, respectively (Table 2). This incongruence in how changes to amino acid 345 differentially influence the catalysis and assembly of Form IB and IC Rubiscos underpins the challenge of using rationale design approaches to identify "all-purpose" amino acid substitutions that can benefit catalysis between, and within, differing Rubisco lineages [1,13,22,47].

\subsection{How Do the K83Q andR252L Substitutions Function Cooperativly to Reduce RsRubisco Biogenesis?}

K83 and R252 in RsRubisco are located, respectively, in strand C of the RbcL N-domain and $\alpha$-helix 3 of the $\alpha / \beta$-barrel (Figure 7a). Their distant locations from the catalytic sites are in accordance with our findings that the mutations K83Q and R252L, both singly (RsRubisco chimers YZ1f and YZ1g) and in combination (YZ1c), have no significant effect on catalysis (Table 2). RsRubisco biogenesis was not affected in YZ1 chimers containing only one of these mutations (chimers YZ1d to g), but was reduced by $\sim 40 \%$ when both were present (YZ1 and YZ1a to c, Table 2). How the K83Q and R252L substitutions work in combination, but not in isolation, to reduce the level of RsRubisco is unclear. It is possible that the mutations reduce $R s R b c L$ compatibility with one or more components of the E. coli protein folding machinery that impairs holoenzyme assembly or alters the stability of the $\mathrm{L}_{8} \mathrm{~S}_{8}$ complex. As summarized in Table 1, a number of single amino acid mutations are known to enhance cyanobacteria Rubisco biogenesis in E. coli. For TeRubisco, the solubility-enhancing F345I and P415A mutations were able to function in a cumulative fashion to further augment solubility (Table 1). It is proposed that these improvements arose by improving the compatibility of RbcL with components of the E. coli protein folding machinery [22]. It is known that chaperonin (GroELS) availability, but not DnaK, DnaJ, GrpE or Trigger Factor, has a pervasive influence on SeRubisco biogenesis in E. coli [29,32]. Sequence complementarity with E. coli GroELS has been used to explain the vast difference is the assembly capabilities of differing cyanobacteria Rubisco (e.g., PCC7002 Rubisco is produced at $<0.5 \%$ CSP [32], SeRubisco at $~ 1.3 \%$ CSP and TeRubisco at 7\% CSP [22,48]) and with RsRubisco (5\% CSP, Table 2). It is therefore possible that the K84Q and R253L mutations in combination reduce RsRbcL compatibility with GroELS to impair RsRubisco biogenesis.

The evaluation of the RsRubisco $\mathrm{L}_{8} \mathrm{~S}_{8}$ crystal structure (Figure $7 \mathrm{~b}$ ) showed that $\mathrm{R} 252$ is located near the surface of the inner solvent channel that traverses the $\mathrm{L}_{8} \mathrm{~S}_{8}$ structure and is situated at the edge of the interface of adjoining large subunits that are arranged head to tail in each $\mathrm{L}_{2}$ unit (Figure 7c). The adjacent R253 residue is conserved among Form I Rubisco and forms a conserved salt bridge with E109 in the adjoined RbcL of each $\mathrm{L}_{2}$ (Figure 7c). While this intradimer interaction is hypothesized to maintain $\mathrm{L}_{2}$ 's structural integrity [49], our findings suggest the R252L substitution does not disturb this Arg-Glu salt bridge as RsRubisco synthesis and stability seems unaffected (Table 2). In contrast to $\mathrm{R} 252, \mathrm{~K} 83$ is a solvent-exposed outer surface residue and independent of any inter-subunit interactions (Figure $7 \mathrm{~b}$ ). Curiously, the YZ1 chimers incorporating K83Q showed a faster mobility through native PAGE, independent of other amino acid substitutions (Figure 6), suggesting the mutation alters the net surface charge of the protein or influences RsRubisco quaternary structure, but without an effect on catalysis (Table 2). The disparate locations of the K83R and R252L mutations in the RsRubisco do not support the hypothesis that they jointly function to reduce RsRubisco content in E. coli through destabilization of the $\mathrm{L}_{8} \mathrm{~S}_{8}$ complex. 


\subsection{Understanding the Basis of RDE Selection}

The adage that "you get what you screen for" highlights how crucial it is to ensure any directed evolution screen can select for a desired fitness trait with high fidelity $[50,51]$. The production of false positives commonly compromises the fidelity of RDE screens, especially those using PRK expressing wild-type E. coli (Figure 1a). In the MM1 gap $A^{-}$mutant RDE screen, the impaired cell viability associated with blocking glycolysis/gluconeogenesis by deleting glceraldehyde-3-phosphate dehydrogenase (Figure $1 b$ ) reduces the frequency of false positives $[24,26]$ which primarily occur from the transposon-interrupted expression of PRK [25]. The selection of these false positives in the XL1-Blue-based RDE2 screen was prevented using PRK:NPTII fusion so that PRK production and kanamycin resistance are linked, thereby preventing the selection of PRK-silenced mutants (Figure 1c). While initial tests indicated the suitability of the JM109(DE3) strain for RDE3 selection (Figure 4), a false positive production rate of approximately $0.04 \%$ was found when more cells were grown on non-permissive, high arabinose LB media (Figure $5 b$ ). Curiously, no sequence changes were evident in the purified pACYC ${ }^{\text {rk:kan }}$ or the pYZRsLS from the eight WT control colonies that grew. A comparable frequency of false positives was also identified in the RDE3-mutant RsRubisco screen (Figure $5 b$ ), in which again the sequence integrity of pACYC ${ }^{\text {prk:kan }}$ was maintained, and only one (YZ1) of the 33 mutant pYZRsLS plasmids re-transformed into RDE3 survived re-selection on high arabinose. The growth of the false positives in the initial RDE3 screens therefore arose independently of changes to either RPK:NPTII or RsRubisco expression. This suggests the false positives may result from chromosomal mutations that alter JM109(DE3) cellular metabolism to dampen its sensitivity to PRK production. This hypothesis is consistent with our finding that other E. coli strains (e.g., DB3.1, BL21(DE3) and BW25113) show resistance to PRK:NPTII production (Figure 4). Current research is underway to identify the genetic and/or metabolic basis for the contrasting sensitivities of $E$. coli strains to PRK production as a means to improve the fidelity of RDE screens.

\subsection{Pathways for Evolving RsRubisco Further-Why and How?}

Our interest in continuing to explore the evolutionary potential of RsRubisco stems from its relatedness to the Form ID "red-Rubisco" lineage that comprises red algae Rubisco isoforms whose high $S_{C / O}$ and carboxylation efficiencies dramatically exceed those of crop plants $[16,18]$. While optimizing the fidelity of the RDE3 to avoid false positive selection is desirable, we found it is not critical if suitable care is taken to re-screen selected RsRubisco mutants (i.e., confirming that Rubisco is improving RDE3 fitness, Figure 5c) before pursuing Rubisco biochemical analyses. As the carboxylase improved YZ1i (Y345F) and biogenesis-impaired YZ1c (R83Q, R252L) mutants offer alternative starting points in the RsRubisco evolutionary landscape, separately evolving them using RDE3 and comparing the biochemical fitness traits selected (solubility and/or kinetic) would provide valuable strategical guidance to successive rounds of evolution.

Incorporating the $R$. sphaeroides chaperonin folding machinery components into RDE3 would alter-and possibly benefit- the RsRubisco evolutionary fitness landscape that can be surveyed. A similar approach taken with SeRubisco found that the inclusion of the Rubisco-specific post-chaperonin assembly chaperone $\mathrm{RbcX}$ altered the fitness landscape of the MM1 screen, with different mutants selected compared with a screen lacking RbcX [27]. This supported an earlier hypothesis that Rubisco evolution is influenced-and possibly even constrained - by the need to maintain complementarity with the protein folding/assembly machinery of a cell [24]. This appears particularly apparent for Form IB plant Rubiscos, whose assembly in $E$. coli requires five compatible molecular partners (i.e., the Rubisco-specific chaperones Raf1, RbcX, Raf2, BSD2 and Cpn60 $\alpha \beta 20$ chaperonin cages $[37,52,53])$. Thus far, maintaining sequence compatibility between Raf1 and $\mathrm{RbcL}$ appears to be the most important factor influencing plant Rubisco biogenesis [54]. Our findings that the R83Q and R252L substitutions inexplicably impair RsRubisco biogenesis in E. coli suggest sequence compatibility between RbcL and that the bacterial GroELS protein folding machinery also impacts Rubisco biogenesis potential. 


\section{Materials and Methods}

\subsection{Comparing the PRK Sensitivity of Different E. coli Strains}

The pACYC ${ }^{\text {rk:kan }}$ plasmid [22] was transformed into $\mathrm{CaCl}_{2}$-competent JM109(DE3), XL1-B, DH5 $\alpha$, DB3.1, BL21(DE3), and BW25113 E. coli cells, and a colony of each was grown in LB-Chlor $\left(30 \mu \mathrm{g} \cdot \mathrm{mL}^{-1}\right)$ at $25{ }^{\circ} \mathrm{C}$. At an absorbance $\left(\mathrm{A}_{600}\right)$ of 0.6 , the cultures were diluted by $10^{-4}$ and $20 \mu \mathrm{L}$ was plated onto LB-Chlor plates containing $0,0.05 \%, 0.1 \%, 0.25 \%(w / v)$ L-arabinose with/without $100 \mu \mathrm{g} \cdot \mathrm{mL}^{-1}$ kanamycin. Colony growth at $25{ }^{\circ} \mathrm{C}$ in air containing $2 \%(v / v) \mathrm{CO}_{2}$ was monitored up to 5 days. Electro-competent RDE3 cells (i.e., pACYC ${ }^{\text {rk:kan }}$ transformed JM109(DE3)) in 10\% (v/v) glycerol were $\mathrm{N}_{2}$ frozen and stored at $-80^{\circ} \mathrm{C}$.

\subsection{Library Construction and Rubisco Selection Using the RDE Screening}

Figure 3 provides a general summary of an RDE-directed evolution experiment. The pilot RDE3 RsRubisco evolution experiment undertaken in this study is summarized in Figure 5. The 1965-bp synthetic Rs-rbcLS operon in which the codon use was modified to match the tobacco $r b c L$ gene (Genbank Accession KM464722) was PCR-amplified using primer 1355 (5'ATCGAGGTCTCGCCATATGGCACCACAAACAGAGAC-3' ', BsaI site underlined) and primer 1356 (5'-GCATGGTCTCCAAGCATCTCGAGCTCAGATCTGTC-3' , BsaI site underlined) and cloned into a modified pTriEx-2 Amp plasmid (Novagen, Addgene, Cambridge, Massachusetts, USA) to give plasmid pYZRsLS (Genbank Accession MN541175, Figure 5a). The $13 \mathrm{~N}$-terminal amino acids of RsRbcL coded in pYZRsLS have been replaced with the $12 \mathrm{~N}$-terminal amino acids from the tobacco RbcL (Figure A1). In pYZRsLS the BsaI sites flanking the Rs-rbcLS operon are positioned downstream of the T7 promoter and adjacent to the T7 terminator. A mutant Rs-rbcLS library was amplified from pYZRsLS with primers 1355 and 1356 using the Genemorph II Random Mutagenesis kit (Agilent Technologies, Santa Clara, CA, USA) over 25 cycles as per the manufacturer's recommendations. The amplified Rs-rbcLS mutant library was digested with BsaI, ligated into BsaI cut pYZRsLS and electroporated (1.8 kV pulse) into $25 \mu \mathrm{L}$ RDE3 cells. RDE3 was also transformed with non-mutated pYZRsLS as the wild-type (WT) control. The cells were added to $1 \mathrm{~mL}$ LB, grown for $1 \mathrm{~h}$ at $37^{\circ} \mathrm{C}, 5 \mu \mathrm{L}$ diluted and plated on non-selective media (LB-chlor-amp; $16 \mu \mathrm{g} / \mathrm{mL}$ chloramphenicol and $100 \mu \mathrm{g} / \mathrm{mL}$ ampicillin) to determine the colony forming unit (cfu) size of the WT and mutant RsRubisco library. The mutant pYZRsLS plasmids from 10 colonies grown on permissive media were transformed into XL1-Blue (LB-amp selected), purified and fully sequenced. The Rs-rbcLS mutational frequency was 2.4 mutations per $\mathrm{kb}$.

The remaining transformed RDE cells were pelleted $(6000 \times g, 1 \mathrm{~min})$, suspended in $0.2 \mathrm{~mL} \mathrm{LB}$ and plated onto LB-arabinose selection (LB-chlor-amp plates containing $125 \mu \mathrm{g} / \mathrm{mL}$ kanamycin, $75 \mu \mathrm{M}$ IPTG and $0.25 \%(w / v)$ arabinose, Figure 5b). The RDE3-WT and RDE3-mutant RsRubisco library plates were grown at $25^{\circ} \mathrm{C}$ for $3-7$ days in air containing $2 \%(v / v) \mathrm{CO}_{2}$. All colonies from both plates were colony picked and grown in $1 \mathrm{~mL}$ LB-chlor-amp, their plasmids were purified and the pYZRsLS re-transformed into XL-1Blue (LB-Amp selection), and then purified for NdeI mapping (expect 3822, 2177 and 1020-bp products) before transforming into RDE3 for the re-screening of selection fitness.

Colonies of the RDE3-rescreened cells were grown to an $\mathrm{OD}_{600}$ of 0.6 in $1 \mathrm{~mL}$ LB-chlor-amp, diluted $10^{-4}$ with LB and $20 \mu \mathrm{L}$ of cells plated on LB-arabinose selection (Figure $5 \mathrm{c}$ ). Of the 41 plasmids re-screened (including eight from the WT screen, Figure 5b) only one, the pYZ1 mutant, improved RDE3 growth on the LB-arabinose $(0.25 \% w / v$, Figure $5 c)$. The Rs-rbcLS operon in pYZ1 contained five nucleotide substitutions that coded four RbcL amino acid changes, from which nine YZ1 RsRubisco derivatives were generated by restriction cloning so that each chimer only coded one to three of each mutation (Figure 5d).

\subsection{Rubisco Content and Catalysis}

JM109(DE3) transformed with pYZRsLS and each pYZ1 derivative were grown at $28{ }^{\circ} \mathrm{C}$ and RsRubisco expression induced for $6 \mathrm{~h}$ with $0.5 \mathrm{mM}$ IPTG before harvesting by centrifugation (10 min, 
$4{ }^{\circ} \mathrm{C}, 6200 \times g$ ) and replica cell pellet aliquots $\mathrm{N}_{2}$ frozen and stored at $-80^{\circ} \mathrm{C}$ (Figure 3c). The soluble and total (lysate) proteins in cell pellets from $10 \mathrm{~mL}$ of cultured cells were analyzed by SDS-PAGE, native PAGE and immunoblot analysis as described [55]. The Rubisco content in the E. coli soluble protein was quantified by ${ }^{14} \mathrm{C}-\mathrm{CABP}$ binding as described [38]. The same soluble protein sample was used to measure $k_{\text {cat }}{ }^{C}$ and $K_{C}$ using ${ }^{14} \mathrm{CO}_{2}$-fixation assays as described [22] using $0-170 \mu \mathrm{M}^{14} \mathrm{CO}_{2}$ in assays equilibrated with $0,20 \%, 35 \%$ or $50 \% \mathrm{O}_{2}(v / v)$ in $\mathrm{N}_{2}$. The increase in $K_{C}$ with increasing $\left[\mathrm{O}_{2}-\right]$ was plotted and the slope of the linear fit used to derive $K_{O}$. $S_{C / O}$ was quantified using the $\left[1{ }^{3} \mathrm{H}\right]-\mathrm{RuBP}$ consumption assay as described [41] using RsRubisco purified from $\sim 40 \mathrm{~mL}$ of cultured cells (Figure 3c) by rapid ion exchange and size exclusion (Superdex 200, GE Life Science, Chicago, IL, USA) as described [42]. Soluble protein concentration was measured using the dye-binding Coomassie Plus Kit (Thermo Fisher Scientific, Waltham, MA, USA) against bovine serum albumin.

\section{Conclusions}

This study provides another demonstration of how directed evolution can improve the carboxylase properties of Rubisco. As shown here, key challenges with RDE screens include differentiating the Rubisco mutants that enhance cell fitness from false positives and then distinguishing carboxylation enhancing mutations from those that improve Rubisco biogenesis. Success is also dependent on tailoring selection screen conditions to the substrate Rubisco being evolved; that is, determining the optimal arabinose and IPTG concentrations for PRK and Rubisco production, keeping in mind that Rubisco production itself impairs E. coli viability [25]. An ongoing consideration is the extent to which the red-type RsRubisco might serve as a suitable surrogate to sequentially evolve its properties towards the high $S_{\mathrm{CO}}$, high carboxylation efficiency properties of the related "better" red algae Rubisco. One possible objective might be to replace plant Rubisco with a kinetically improved RsRubisco, although this will depend on whether its folding and assembly requirements are met by plant chloroplasts. Current evidence suggests the extent of prokaryotic Rubisco expression in E. coli is a poor indicator of its biogenesis potential in tobacco [20-22]. An alternative to evolving RsRubisco might be to evolve plant Rubisco itself using an RDE screen incorporating the chloroplast protein folding machinery $[53,56]$. As the components of the plant Rubisco expression systems are primarily T7-promoter regulated [37,57], our JM109(DE3)-based RDE3 screen appears to be a suitable selection host for such a directed evolution endeavor.

Author Contributions: Y.Z. and S.W. contributed equally to the conceptualization, formal analysis, and writing of the article. Funding was awarded to S.W.

Funding: This research was supported by the Australian Government through the Australian Research Council Centre of Excellence for Translational Photosynthesis CE140100015.

Conflicts of Interest: The authors declare no conflict of interest. The funders had no role in the design of the study; in the collection, analyses, or interpretation of data; in the writing of the manuscript, or in the decision to publish the results.

\section{Abbreviations}

Raf1

Raf2

BSD2

$\mathrm{RbcX}$

cfu

RuBP

$\mathrm{S}_{\mathrm{C} / \mathrm{O}}$

$\mathrm{k}_{\text {cat }} \mathrm{C}$

$\mathrm{k}_{\text {cat }} \mathrm{O}$

$\mathrm{K}_{\mathrm{C}}$

$\mathrm{K}_{\mathrm{C}}{ }^{21 \% \mathrm{O} 2}$

$\mathrm{K}_{\mathrm{O}}$

PRK
Rubisco accumulation factor 1

Rubisco accumulation factor 2

Bundle Sheath Defective II Rubisco chaperone

Rubisco specific chaperone

Colony forming units

Ribulose-1,5-bisphosphate

Specificity for $\mathrm{CO}_{2}$ over $\mathrm{O}_{2}$

Substrate saturated carboxylation rate

Substrate saturated oxygenation rate

Apparent $K_{\mathrm{m}}$ for $\mathrm{CO}_{2}$

Apparent $K_{\mathrm{m}}$ for $\mathrm{CO}_{2}$ under ambient $(20.6 \%(v / v)) \mathrm{O}_{2}$

Apparent $K_{\mathrm{m}}$ for $\mathrm{O}_{2}$

Phosphoribulokinase 


\section{Appendix A}

\section{(a) RbcL alignment}

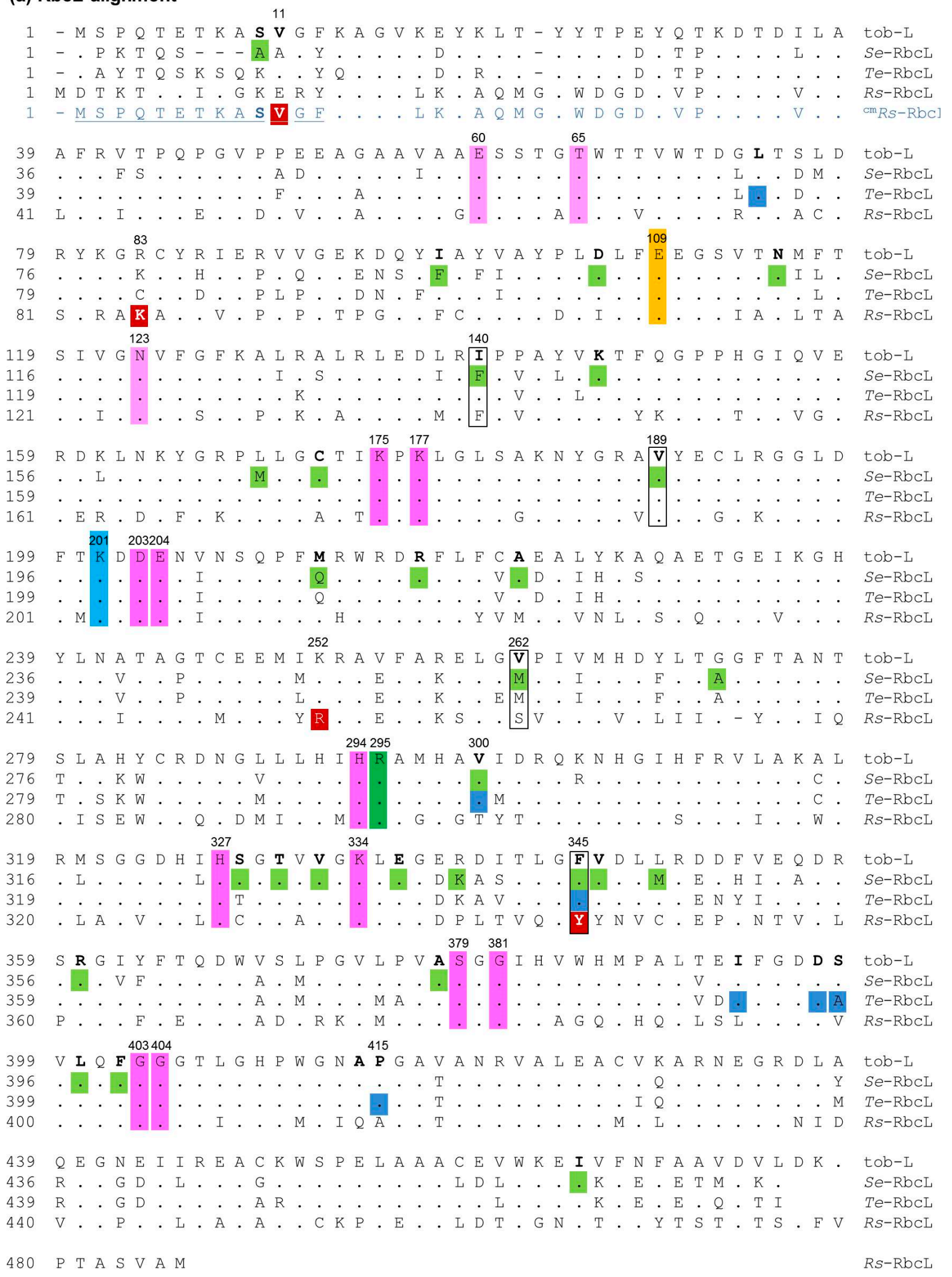

Figure A1. Cont. 


\section{(b) RbcS alignment}

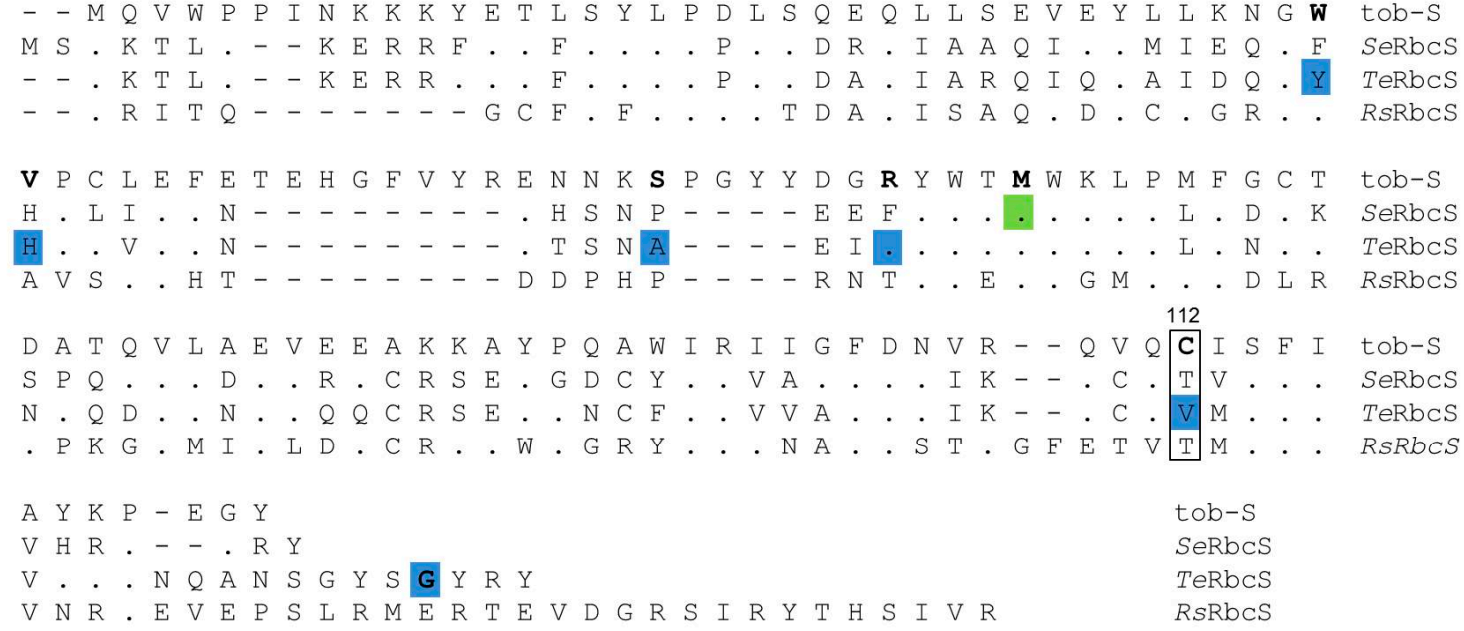

RDE \& MM1 selected SeRubisco mutations (see Table A1).

RDE2 selected TeRubisco mutations (see Table A1).

RDE3 selected RsRubisco mutations (see Table 2).

Residues selected in multiple RDE screens

Conserved catalytic pocket residues (including R295

Critical catalytic K201

E109 that forms an salt bridge with $\mathrm{R} 253$ in adjoining RbcL

Figure A1. Alignments of (a) RbcL and (b) RbcS for Rubisco from Nicotiana tabacum (tob-L, Z00044; tob-S, XP_016440853), Synehcococcus elongatus PCC6301 (SeRbcL, P00880.2; SeRbcS P04716), Thermosynehcococcus elongatus BP1 (TeRbcL, NP_682296.1; TeRbcS NP_682294.1) and Rhodobacter spharoides (RsRbcL, WP_002721829.1; RsRbcS WP_002721826.1). The first 39 amino acids of the altered codon modified $(\mathrm{cm})$ RsRbcL N-terminus coded in pYZRsLS are shown in blue text. Sequences were Clustal W-aligned, with only residues differing from the tob sequences shown. Dashes were included to improve the alignment of any missing residues. Amino acid numbering is relative to tob- $\mathrm{L}$ and tob-S. Coloring is as indicated in the legend under panel (b).

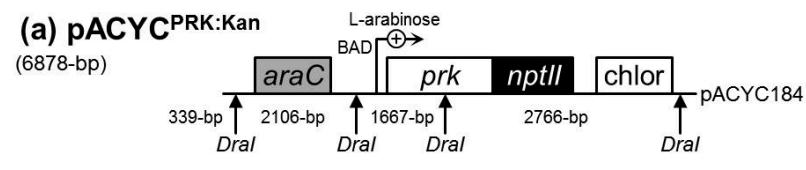

(b) Dral cut purified PACYC ${ }^{\text {PRK:Kan }}$

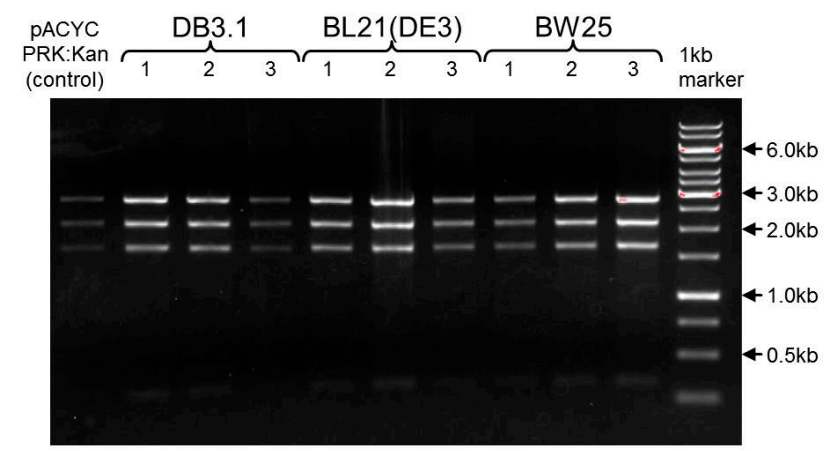

Figure A2. Restriction mapping of $\mathrm{pACYC}^{\text {PRK:Kan }}$. (a) The plasmid map and (b) DraI restriction mapping of the source pACYC ${ }^{P R K: K a n}$ plasmid (control) and that purified from three separate colonies of the E. coli strains indicate that they survived growth on selective media containing $0.25 \%(w / v)$ L-Arabinose (Figure 4). 
Table A1. Summary of directed evolution Rubisco mutants and the content and catalytic properties selected using E. coli and Ralstonia eutrophus screens.

\begin{tabular}{|c|c|c|c|c|c|c|c|c|c|c|c|c|c|c|}
\hline Rubisco Origin & Mutation (s) & $\begin{array}{l}\text { Plant RbcL } \\
\text { Numbering }\end{array}$ & $\begin{array}{c}K_{C} \\
(\mu \mathrm{M})\end{array}$ & $\begin{array}{c}K_{C}^{21 \% 02} \\
(\mu \mathrm{M})\end{array}$ & $\begin{array}{l}k_{c a t}{ }^{c} \\
\left(\mathrm{~s}^{-1}\right)\end{array}$ & $\begin{array}{c}k_{c a t}{ }^{C} / K_{C} \\
\left(\mathrm{~s}^{-1} \cdot \mathrm{mM}^{-1}\right)\end{array}$ & $\begin{array}{c}k_{c a t}{ }^{c} / K_{c}{ }_{c}^{21 \% O 2} \\
\left(\mathrm{~s}^{-1} \cdot \mathrm{mM}^{-1}\right)\end{array}$ & $\begin{array}{c}K_{O} \\
(\mu \mathrm{M})\end{array}$ & $\begin{array}{l}k_{c a t}{ }^{O} \\
\left(\mathrm{~s}^{-1}\right)\end{array}$ & $k_{c a t}{ }^{o} / K_{O}$ & $s_{C / O}$ & $\begin{array}{c}K_{R u B P} \\
(\mu \mathrm{M})\end{array}$ & $\begin{array}{l}\text { Rubisco } \\
\text { (\%CSP) }\end{array}$ & RDE Strain \\
\hline \multirow{4}{*}{$\begin{array}{c}\text { Synchococcus } \\
\text { PCC6301 }\left(\mathrm{L}_{8} \mathrm{~S}_{8}\right)\end{array}$} & WT & - & 273 & - & 11.4 & 42 & - & - & - & - & 44.0 & 64 & 1.0 & \multirow{4}{*}{$\begin{array}{c}\text { E. coli K12 } \\
\text { Ref [29] }\end{array}$} \\
\hline & M259T & 262 & 237 & - & 12.8 & 54 & - & - & - & - & 43.0 & 67 & 6.0 & \\
\hline & A8S/M259T & $10 / 262$ & 216 & - & 11.4 & 53 & - & - & - & - & 41.0 & 48 & 5.5 & \\
\hline & $\mathrm{F} 342 \mathrm{~S} / \mathrm{M} 259 \mathrm{~T}$ & $345 / 262$ & 207 & - & 10.0 & 48 & - & - & - & - & 38.0 & 34 & 3.5 & \\
\hline \multirow{12}{*}{$\begin{array}{l}\text { Synchococcus } \\
\left.\text { PCC6301 (L } \mathrm{L}_{8} \mathrm{~S}_{8}\right)\end{array}$} & WT & - & 200 & 242 & 11.8 & 59 & 48.7 & 1191 & 1.7 & 1.42 & 41.5 & 44 & 0.2 & \multirow{12}{*}{$\begin{array}{c}M M 1 \\
\operatorname{Ref}[30]\end{array}$} \\
\hline & F345I & 345 & 208 & 266 & 10.1 & 49 & 38.0 & 908 & 1.2 & 1.33 & 36.6 & 31 & 3.4 & \\
\hline & $\mathrm{I} 174 \mathrm{~V}$ & 174 & 233 & 283 & 10.2 & 44 & 36.0 & 1174 & 1.2 & 1.02 & 42.9 & 33 & 1.1 & \\
\hline & $\mathrm{F} 345 \mathrm{~L}$ & 345 & 245 & - & 9.8 & 40 & - & - & - & - & 40.0 & 93 & 1.9 & \\
\hline & Q212L & 212 & 370 & 444 & 9.9 & 27 & 22.3 & 1252 & 0.9 & 0.72 & 37.4 & 31 & 1.7 & \\
\hline & L348M & 348 & 287 & - & 11.3 & 39 & - & - & - & - & 35.1 & 84 & - & \\
\hline & N115S & 115 & 191 & - & 9.0 & 47 & - & - & - & - & 43.5 & 44 & 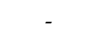 & \\
\hline & A272G & 272 & 244 & - & 9.7 & 40 & - & - & - & - & 40.2 & 34 & - & \\
\hline & K339R & 339 & 148 & - & 10.1 & 68 & - & - & - & - & 43.0 & 35 & - & \\
\hline & M262T & 262 & - & - & - & - & - & - & - & - & - & - & 0.9 & \\
\hline & M169L & 169 & - & - & - & - & - & - & - & - & - & - & 0.8 & \\
\hline & L161M & 161 & - & - & - & - & - & - & - & - & - & - & 1.1 & \\
\hline \multirow{2}{*}{$\begin{array}{c}\begin{array}{c}\text { Synech.PCC7002 } \\
\left(\mathrm{L}_{8} \mathrm{~S}_{8}\right)\end{array} \\
\end{array}$} & WT & & 132 & - & 6.7 & 51 & - & - & - & - & - & 52 & - & \multirow{2}{*}{$\begin{array}{c}\text { BL21(DE3) } \\
\operatorname{Ref}[58]\end{array}$} \\
\hline & $\mathrm{E}^{2} 9 \mathrm{~V}^{\mathrm{S}} / \mathrm{D} 82 \mathrm{G}^{\mathrm{S}}$ & $\mathrm{E} 51 \mathrm{~V}^{\mathrm{S}} / \mathrm{D} 96 \mathrm{G}^{\mathrm{S}}$ & 200 & - & 14.6 & 74 & - & - & - & - & - & 50 & - & \\
\hline \multirow{11}{*}{$\begin{array}{l}\text { Synchococcus } \\
\text { PCC6301 }\left(\mathrm{L}_{8} \mathrm{~S}_{8}\right)\end{array}$} & WT & - & 248 & - & 12.9 & 52 & - & - & - & 0.9 & 56.1 & - & - & \multirow{11}{*}{$\begin{array}{c}\text { MM1 } \\
\operatorname{Ref}[27]\end{array}$} \\
\hline & F140I & 140 & 129 & - & 19.4 & 150 & - & - & - & 2.9 & 51.3 & - & - & \\
\hline & $\mathrm{C} 172 \mathrm{G}$ & 172 & 493 & - & 12.8 & 26 & - & - & - & 0.4 & 59.6 & - & - & \\
\hline & V189I & 189 & 160 & - & 14.3 & 89 & - & - & - & 1.8 & 49.2 & - & - & \\
\hline & V221I & 221 & 181 & - & 2.5 & 14 & - & - & - & 0.3 & 57.9 & - & - & \\
\hline & V346L & 346 & 256 & - & 4.3 & 17 & - & - & - & 0.3 & 56.9 & - & - & \\
\hline & V346I & 346 & 274 & - & 7.2 & 26 & - & - & - & 0.5 & 54.4 & - & - & \\
\hline & S398C & 398 & 322 & - & 18.6 & 58 & - & - & - & 1.0 & 56.2 & - & - & \\
\hline & $\mathrm{I} 465 \mathrm{~V}$ & 465 & 298 & - & 14.3 & 48 & - & - & - & 0.9 & 53.7 & - & - & \\
\hline & F345I & 345 & 274 & - & 11.2 & 41 & - & - & - & 0.8 & 52.1 & - & - & \\
\hline & F140I/F345I & $140 / 345$ & 218 & - & 15.6 & 72 & - & - & - & 1.2 & 59.3 & - & - & \\
\hline \multirow{15}{*}{$\begin{array}{l}\text { Thermosynech } \\
\text { elongatus }\left(\mathrm{L}_{8} \mathrm{~S}_{8}\right)\end{array}$} & WT & - & - & 107 & 6.6 & - & 70 & - & - & - & 53.3 & 36 & 6.6 & \multirow{19}{*}{$\begin{array}{c}R D E 2 \\
X L 1-B \\
\operatorname{Ref}[22]\end{array}$} \\
\hline & F345I & 345 & - & 101 & 6.9 & - & 47 & - & - & - & 48.0 & - & 14.6 & \\
\hline & P415A & 415 & - & 111 & 6.9 & - & 62 & - & - & - & 52.6 & - & 10.4 & \\
\hline & V300A & 300 & - & 135 & 6.6 & - & 49 & - & - & - & 51.9 & - & 7.1 & \\
\hline & F345I/P415A & $345 \mathrm{I} / 415$ & - & 102 & 4.8 & - & 47 & - & - & - & 49.2 & - & 17.5 & \\
\hline & $\mathrm{P} 415 \mathrm{~A} / \mathrm{V} 9 \mathrm{M}^{\mathrm{S}}$ & $415 / 112^{\mathrm{S}}$ & - & 93 & 9.5 & - & 100 & - & - & - & 56.3 & - & 20.4 & \\
\hline & $\mathrm{P} 415 \mathrm{~A} / \mathrm{A} 48 \mathrm{~V}^{\mathrm{S}}$ & $415 / 58^{\mathrm{S}}$ & - & 105 & 8.8 & - & 84 & - & - & - & 48.0 & - & 9.7 & \\
\hline & $\mathrm{P} 415 \mathrm{~A} / \mathrm{H} 37 \mathrm{~L}^{\mathrm{S}}$ & $415 / 39^{\mathrm{S}}$ & - & 100 & 8.4 & - & 84 & - & - & - & 49.7 & - & 11.1 & \\
\hline & $\mathrm{P} 415 \mathrm{~A} / \mathrm{Y} 36 \mathrm{~N}^{\mathrm{S}} / \mathrm{G} 112 \mathrm{D}^{\mathrm{S}}$ & $415 / 38^{\mathrm{S}} / 122^{\mathrm{S}} / 123^{\mathrm{S}}$ & - & 94 & 9.3 & - & 99 & - & - & - & 47.7 & - & 9.7 & \\
\hline & $\mathrm{P} 415 \mathrm{~A} / \mathrm{Y} 36 \mathrm{~N}^{\mathrm{S}} / \mathrm{R}^{\mathrm{S}} 1 \mathrm{H}^{\mathrm{S}}$ & $415 / 38^{\mathrm{s}} / 65^{\mathrm{s}}$ & - & 120 & 8.0 & - & 68 & - & - & - & 51.8 & - & 13.6 & \\
\hline & $\mathrm{P} 415 \mathrm{~A} / \mathrm{A} 398 \mathrm{~T} / \mathrm{A} 48 \mathrm{~V}^{\mathrm{S}}$ & $415 / 398 / 58^{\mathrm{S}}$ & - & 105 & 8.1 & - & 75 & - & - & - & 45.5 & - & 13.3 & \\
\hline & P415A/L74M/D397N & $415 / 74 / 397$ & - & 92 & 8.2 & - & 90 & - & - & - & 51.8 & - & 12.5 & \\
\hline & P415A/A414T & $415 / 414$ & - & 102 & 8.0 & - & 78 & - & - & - & 55.8 & - & 13.9 & \\
\hline & $\mathrm{P} 415 \mathrm{~A} / \mathrm{I} 393 \mathrm{M}$ & $415 / 393$ & - & 90 & 7.8 & - & 87 & - & - & - & 48.1 & - & 16.6 & \\
\hline & P415A/A398T & $415 / 398$ & - & 110 & 6.4 & - & 59 & - & - & - & 50.5 & - & 16.6 & \\
\hline \multirow{4}{*}{$\begin{array}{c}\text { Synchococcus } \\
\left.\text { PCC6301 (L } \mathrm{L}_{8} \mathrm{~S}_{8}\right)\end{array}$} & WT & - & - & 251 & 12.6 & - & 50 & - & - & - & 46.0 & 44 & 1.3 & \\
\hline & F345I & 345 & - & 285 & 10.3 & - & 36 & - & - & - & 42.0 & - & 14.4 & \\
\hline & F140I & 140 & - & 211 & 11.1 & - & 53 & - & - & - & 46.0 & - & 6.3 & \\
\hline & V189I & 189 & - & 186 & 10.6 & - & 57 & - & - & - & 39.0 & NA & 6.2 & \\
\hline
\end{tabular}


Table A1. Cont.

\begin{tabular}{|c|c|c|c|c|c|c|c|c|c|c|c|c|c|c|}
\hline Rubisco Origin & Mutation (s) & $\begin{array}{c}\text { Plant RbcL } \\
\text { Numbering }\end{array}$ & $\begin{array}{c}K_{C} \\
(\mu \mathrm{M})\end{array}$ & 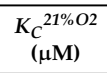 & $\begin{array}{l}k_{\text {cat }}{ }^{c} \\
\left(\mathrm{~s}^{-1}\right)\end{array}$ & $\begin{array}{c}k_{\text {cat }}{ }^{C} / K_{C} \\
\left(\mathrm{~s}^{-1} \cdot \mathrm{mM}^{-1}\right)\end{array}$ & $\begin{array}{c}k_{c a t}^{C} / K_{C} 21 \% O 2 \\
\left(\mathbf{s}^{-1} \cdot \mathbf{m M}^{-1}\right)\end{array}$ & $\begin{array}{c}K_{O} \\
(\mu \mathrm{M})\end{array}$ & $\begin{array}{l}k_{c a t}{ }^{O} \\
\left(\mathrm{~s}^{-1}\right)\end{array}$ & $k_{c a t}{ }^{O} / K_{O}$ & $s_{C / O}$ & $\begin{array}{c}K_{R u B P} \\
(\mu \mathrm{M})\end{array}$ & $\begin{array}{l}\text { Rubisco } \\
\text { (\%CSP) }\end{array}$ & RDE Strain \\
\hline \multirow{5}{*}{$\begin{array}{l}\text { RhodospirIllum } \\
\text { Rubrum }\left(\mathrm{L}_{2}\right)\end{array}$} & WT & & 149 & - & 12.3 & 83 & - & 159 & 1.4 & 9.0 & 9.0 & 63 & 0.2 & \multirow{5}{*}{$\begin{array}{c}\text { MM1 } \\
\operatorname{Ref}[26]\end{array}$} \\
\hline & D117V & 129 & 196 & - & 7.3 & 38 & - & 199 & 1.5 & 8.0 & 5.3 & 55 & 0.6 & \\
\hline & $\mathrm{D} 117 \mathrm{H}$ & 129 & 192 & - & 7.5 & 39 & - & 153 & 1.1 & 7.0 & 5.3 & 48 & 0.5 & \\
\hline & $\mathrm{H} 44 \mathrm{Q}$ & 56 & 301 & - & 9.3 & 31 & - & 185 & 1.2 & 6.0 & 5.3 & 56 & 0.9 & \\
\hline & $\mathrm{H} 44 \mathrm{~N}$ & 56 & 204 & - & 9.8 & 48 & - & 116 & 1.0 & 9.0 & 5.5 & 59 & 0.7 & \\
\hline \multirow{8}{*}{$\begin{array}{c}\text { Methanococcoides } \\
\text { burtonii } \\
\quad\left(\mathrm{L}_{2}-\mathrm{L}_{10}\right)\end{array}$} & WT & - & 57 & 1337 & 0.6 & 11 & 0.5 & 11 & 0.1 & 8.0 & 1.3 & 4 & 7.0 & \multirow{8}{*}{$\begin{array}{c}\text { MM1 } \\
\operatorname{Ref}[40]\end{array}$} \\
\hline & E138V & 146 & 66 & 543 & 1.0 & 15 & 1.8 & 35 & 0.4 & 11.0 & 1.5 & 2 & 8.0 & \\
\hline & K332E & 336 & 78 & 892 & 1.2 & 15 & 1.4 & 24 & 0.3 & 13.0 & 1.3 & 5 & 6.0 & \\
\hline & T421A & 400 & - & - & 1.3 & - & - & - & - & - & 1.7 & - & 9.0 & \\
\hline & M423V & 402 & - & - & 1.1 & - & - & - & - & - & - & - & 7.0 & \\
\hline & $\mathrm{H} 379 \mathrm{R}$ & 360 & - & - & 0.6 & - & - & - & - & - & - & - & 6.0 & \\
\hline & Y471N & 471 & - & - & 0.9 & - & - & - & - & - & - & - & 4.0 & \\
\hline & G327S & 331/insert|332 & - & - & 0.7 & - & - & - & - & - & - & - & 6.0 & \\
\hline \multirow{5}{*}{$\begin{array}{c}\text { Synechococcus } \\
\text { PCC6301 } \\
\left(\mathrm{L}_{8} \mathrm{~S}_{8}\right)\end{array}$} & WT & - & 186 & - & 3.5 & 22 & - & - & - & - & - & 38 & - & \multirow{5}{*}{$\begin{array}{c}\text { R.capsulatus } \\
\text { SBI/II-mutant } \\
\text { Ref [31] }\end{array}$} \\
\hline & $\mathrm{F} 342 \mathrm{~V}$ & 345 & 256 & - & 2.4 & 12 & - & - & - & - & - & 21 & - & \\
\hline & D103V & 106 & 459 & - & 2.4 & 7 & - & - & - & - & - & 34 & - & \\
\hline & D103N & 106 & 325 & - & 1.8 & 6 & - & - & - & - & - & 36 & - & \\
\hline & D103E & 106 & 301 & - & 1.3 & 3 & - & - & - & - & - & 33 & - & \\
\hline \multirow{4}{*}{$\begin{array}{c}\text { Synechococcus } \\
\text { PCC6301 } \\
\left(\mathrm{L}_{8} \mathrm{~S}_{8}\right)\end{array}$} & WT & - & 186 & - & 4.9 & 26 & - & 850 & - & - & - & 27 & - & \multirow{4}{*}{$\begin{array}{c}\text { R.capsulatus } \\
\text { SBI/II-mutant } \\
\text { Ref [43] }\end{array}$} \\
\hline & D103V & 106 & 388 & - & 4.9 & 13 & - & 866 & - & - & - & 25 & - & \\
\hline & $\mathrm{A} 375 \mathrm{~V}$ & 378 & 143 & - & 0.6 & 4 & - & 1088 & - & - & - & 34 & - & \\
\hline & D103V/A375V & $106 / 378$ & 294 & - & 3.1 & 10 & - & 1153 & - & - & - & 269 & - & \\
\hline \multirow{11}{*}{$\begin{array}{c}\text { Synechococcus } \\
\text { PCC6301 } \\
\left(\mathrm{L}_{8} \mathrm{~S}_{8}\right)\end{array}$} & WT & - & 190 & 247 & 4.3 & 21 & - & 841 & - & - & - & 29 & - & \multirow{11}{*}{$\begin{array}{l}\text { R.capsulatus } \\
\text { SBI/II-mutant } \\
\text { Ref [28] }\end{array}$} \\
\hline & $\mathrm{A} 375 \mathrm{~T}$ & 378 & 146 & & $\begin{array}{l}4.5 \\
0.5\end{array}$ & 3 & - & $\begin{array}{l}0+1 \\
1076\end{array}$ & - & - & - & 37 & - & \\
\hline & M259T & 262 & 147 & 209 & 4.4 & 27 & - & 595 & - & - & - & 30 & - & \\
\hline & A375V/M259T/M571 & $378 / 262 / 81^{\mathrm{S}}$ & 93 & 126 & 2.2 & 22 & - & 716 & - & - & - & 64 & - & \\
\hline & $\mathrm{R} 214 \mathrm{H}$ & 217 & 682 & - & 3.6 & 6 & - & 2152 & - & - & - & 30 & - & \\
\hline & R214H/A375S & $217 / 378$ & 264 & - & 0.6 & 2 & - & 1731 & - & - & - & 25 & - & \\
\hline & T327A & 330 & 273 & - & 2.8 & 11 & - & 1303 & - & - & - & 13 & - & \\
\hline & V186I & 189 & 106 & 145 & 2.8 & 28 & - & 686 & - & - & - & 25 & - & \\
\hline & V186//T327A & $189 / 330$ & 110 & 133 & 2.1 & 18 & - & 1189 & - & - & - & 25 & - & \\
\hline & S325L & 328 & 111 & - & 4.0 & 36 & - & 931 & - & - & - & 251 & - & \\
\hline & S325L/T327A & $328 / 330$ & 142 & - & 2.6 & 21 & - & 577 & - & - & - & 77 & - & \\
\hline \multirow{7}{*}{$\begin{array}{l}\text { Ralstonia eutropha } \\
\text { (Cupriavidus } \\
\text { necator; } \mathrm{L}_{8} \mathrm{~S}_{8} \text { ) }\end{array}$} & WT & & 37 & - & 3.8 & 102 & - & 1149 & - & - & - & 34 & - & \multirow{7}{*}{ 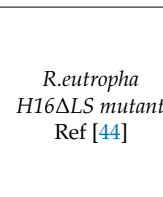 } \\
\hline & Y347V & 345 & 35 & - & 4.1 & 117 & - & 1139 & - & - & - & 34 & - & \\
\hline & A $380 \mathrm{~V}$ & 378 & 34 & - & 0.3 & 9 & - & 1435 & - & - & - & 939 & - & \\
\hline & T330A & 328 & 44 & - & 2.8 & 64 & - & 1087 & - & - & - & 29 & - & \\
\hline & Y348C & 346 & 24 & - & 1.6 & 25 & - & 674 & - & - & - & 36 & - & \\
\hline & T330A/A380V & $328 / 378$ & 28 & - & 0.7 & 25 & - & 1069 & - & - & - & 769 & - & \\
\hline & Y348C/A380V & $346 / 378$ & 20 & - & 0.7 & 35 & - & 652 & - & - & - & 581 & - & \\
\hline
\end{tabular}

\%CSP, Percentage $(w / w)$ cell soluble protein; Red text-kinetic values corrected from those published in Mueller-cajar et al., 2008; (-) value not measured. 


\section{References}

1. Sharwood, R.E. Engineering chloroplasts to improve Rubisco catalysis: Prospects for translating improvements into food and fiber crops. New Phytol. 2017, 213, 494-510. [CrossRef]

2. Ellis, R.J. The most abundant protein in the world. Trends Biochem. Sci. 1979, 4, 241-244. [CrossRef]

3. Young, J.N.; Heureux, A.M.C.; Sharwood, R.E.; Rickaby, R.E.M.; Morel, F.M.M.; Whitney, S.M. Large variation in the Rubisco kinetics of diatoms reveals diversity among their carbon-concentrating mechanisms. J. Exp. Bot. 2016, 67, 3445-3456. [CrossRef] [PubMed]

4. Makino, A. Rubisco and nitrogen relationships in rice: Leaf photosynthesis and plant growth. Soil Sci. Plant Nutr. 2003, 49, 319-327. [CrossRef]

5. Bauwe, H.; Hagemann, M.; Kern, R.; Timm, S. Photorespiration has a dual origin and manifold links to central metabolism. Curr. Opin. Plant Biol. 2012, 15, 269-275. [CrossRef] [PubMed]

6. Sage, R.F.; Sage, T.L.; Kocacinar, F. Photorespiration and the evolution of C4 photosynthesis. Annu. Rev. Plant Biol. 2012, 63, 19-47. [CrossRef] [PubMed]

7. Carmo-Silva, E.; Scales, J.C.; Madgwick, P.J.; Parry, M.A.J. Optimizing Rubisco and its regulation for greater resource use efficiency. Plantcell Environ. 2015, 38, 1817-1832. [CrossRef] [PubMed]

8. Parry, M.A.J.; Andralojc, P.J.; Scales, J.C.; Salvucci, M.E.; Carmo-Silva, A.E.; Alonso, H.; Whitney, S.M. Rubisco activity and regulation as targets for crop improvement. J. Exp. Bot. 2013, 64, 717-730. [CrossRef] [PubMed]

9. Andersson, I.; Backlund, A. Structure and function of Rubisco. Plant Physiol. Biochem. 2008, 46, $275-291$. [CrossRef]

10. Andersson, I. Catalysis and regulation in Rubisco. J. Exp. Bot. 2008, 59, 1555-1568. [CrossRef]

11. Cummins, P.L.; Kannappan, B.; Gready, J.E. Revised mechanism of carboxylation of ribulose-1,5-biphosphate by rubisco from large scale quantum chemical calculations. J. Comput. Chem. 2018, 39, 1656-1665. [CrossRef] [PubMed]

12. Ishikawa, C.; Hatanaka, T.; Misoo, S.; Miyake, C.; Fukayama, H. Functional incorporation of sorghum small subunit increases the catalytic turnover rate of Rubisco in transgenic rice. Plant Physiol. 2011, 156, 1603-1611. [CrossRef] [PubMed]

13. Whitney, S.M.; Sharwood, R.E.; Orr, D.; White, S.J.; Alonso, H.; Galmés, J. Isoleucine 309 acts as a C4 catalytic switch that increases ribulose-1,5-bisphosphate carboxylase/oxygenase (rubisco) carboxylation rate in Flaveria. Proc. Natl. Acad. Sci. USA 2011, 108, 14688-14693. [CrossRef] [PubMed]

14. Spreitzer, R.J.; Peddi, S.R.; Satagopan, S. Phylogenetic engineering at an interface between large and small subunits imparts land-plant kinetic properties to algal Rubisco. Proc. Nat. Acad. Sci. 2005, 102, 17225-17230. [CrossRef] [PubMed]

15. Farquhar, G.D.; von Caemmerer, S.; Berry, J.A. A biochemical model of photosynthetic CO2 assimilation in leaves of C3 species. Planta 1980, 149, 78-90. [CrossRef] [PubMed]

16. Andrews, T.J.; Whitney, S.M. Manipulating ribulose bisphosphate carboxylase/oxygenase in the chloroplasts of higher plants. Arch. Biochem. Biophys. 2003, 414, 159-169. [CrossRef]

17. Long, S.P.; Marshall-Colon, A.; Zhu, X.-G. Meeting the global food demand of the future by engineering crop photosynthesis and yield potential. Cell 2015, 161, 56-66. [CrossRef] [PubMed]

18. Whitney, S.M.; Baldet, P.; Hudson, G.S.; Andrews, T.J. Form I Rubiscos from non-green algae are expressed abundantly but not assembled in tobacco chloroplasts. Plant J. 2001, 26, 535-547. [CrossRef]

19. Lin, M.T.; Hanson, M.R. Red algal Rubisco fails to accumulate in transplastomic tobacco expressing Griffithsia monilis RbcL and RbcS genes. Plant Direct. 2018, 2, e00045. [CrossRef]

20. Long, B.M.; Hee, W.Y.; Sharwood, R.E.; Rae, B.D.; Kaines, S.; Lim, Y.-L.; Nguyen, N.D.; Massey, B.; Bala, S.; von Caemmerer, S.; et al. Carboxysome encapsulation of the $\mathrm{CO}_{2}$-fixing enzyme Rubisco in tobacco chloroplasts. Nat. Commun. 2018, 9, 3570. [CrossRef]

21. Occhialini, A.; Lin, M.T.; Andralojc, P.J.; Hanson, M.R.; Parry, M.A.J. Transgenic tobacco plants with improved cyanobacterial Rubisco expression but no extra assembly factors grow at near wild-type rates if provided with elevated CO(2). Plant J. 2016, 85, 148-160. [CrossRef] [PubMed]

22. Wilson, R.H.; Martin-Avila, E.; Conlan, C.; Whitney, S.M. An improved Escherichia coli screen for Rubisco identifies a protein-protein interface that can enhance $\mathrm{CO}_{2}$-fixation kinetics. J. Biol. Chem. 2018, 293, 18-27. [CrossRef] [PubMed] 
23. Sharwood, R.E.; Ghannoum, O.; Kapralov, M.V.; Gunn, L.H.; Whitney, S.M. Temperature responses of Rubisco from Paniceae grasses provide opportunities for improving $C_{3}$ photosynthesis. Nat. Plants 2016, 2, 16186. [CrossRef] [PubMed]

24. Mueller-Cajar, O.; Whitney, S.M. Directing the evolution of Rubisco and Rubisco activase: First impressions of a new tool for photosynthesis research. Photosynth. Res. 2008, 98, 667-675. [CrossRef] [PubMed]

25. Wilson, R.H.; Whitney, S.M. Improving CO2 fixation by enhancing Rubisco performance. In Directed Enzyme Evolution: Advances and Applications; Alcalde, M., Ed.; Springer International Publishing: Berlin, Germany, 2017; pp. 101-126.

26. Mueller-Cajar, O.; Morell, M.; Whitney, S.M. Directed evolution of Rubisco in Escherichia coli reveals a specificity-determining hydrogen bond in the form II enzyme. Biochemistry 2007, 46, 14067-14074. [CrossRef]

27. Durao, P.; Aigner, H.; Nagy, P.; Mueller-Cajar, O.; Hartl, F.U.; Hayer-Hartl, M. Opposing effects of folding and assembly chaperones on evolvability of Rubisco. Nat. Chem. Biol. 2015, 11, 148-155. [CrossRef]

28. Satagopan, S.; Huening, K.A.; Tabita, F.R. Selection of cyanobacterial Synechococcus sp. Strain PCC 6301 Rubisco variants with improved functional properties that confer enhanced $\mathrm{CO}_{2}$-dependent growth of Rhodobacter capsulatus, a photosynthetic bacterium. mBio 2019, 10, e01537-19. [CrossRef]

29. Greene, D.N.; Whitney, S.M.; Matsumura, I. Artificially evolved Synechococcus PCC6301 Rubisco variants exhibit improvements in folding and catalytic efficiency. Biochem. J. 2007, 404, 517-524. [CrossRef]

30. Mueller-Cajar, O.; Whitney, S.M. Evolving improved Synechococcus Rubisco functional expression in Escherichia coli. Biochem. J. 2008, 414, 205-214. [CrossRef]

31. Smith, S.A.; Tabita, F.R. Positive and negative selection of mutant forms of prokaryotic (cyanobacterial) ribulose-1, 5-bisphosphate carboxylase/oxygenase. J. Mol. Biol. 2003, 331, 557-569. [CrossRef]

32. Emlyn-Jones, D.; Woodger, F.J.; Price, G.D.; Whitney, S.M. RbcX can function as a Rubisco-chaperonin, but is non essential in Synechococcus PCC7942. Plant Cell Physiol. 2006, 47, 1630-1640. [CrossRef] [PubMed]

33. Andrews, T.J.; Ballment, B. The function of the small subunits of ribulose bisphosphate carboxylase-oxygenase. J. Biol. Chem. 1983, 258, 7514-7518. [PubMed]

34. Bracher, A.; Whitney, S.M.; Hartl, F.U.; Hayer-Hartl, M. Biogenesis and metabolic maintenance of Rubisco. Annu. Rev. Plant Biol. 2017, 68, 29-60. [CrossRef]

35. Liu, D.; Ramya, R.C.S.; Mueller-Cajar, O. Surveying the expanding prokaryotic Rubisco multiverse. FEMS Microbiol. Lett. 2017, 364, 16. [CrossRef] [PubMed]

36. Parikh, M.R.; Greene, D.N.; Woods, K.K.; Matsumura, I. Directed evolution of Rubisco hypermorphs through genetic selection in engineered E. coli. Protein Eng. Des. Sel. 2006, 19, 113-119. [CrossRef] [PubMed]

37. Aigner, H.; Wilson, R.H.; Bracher, A.; Calisse, L.; Bhat, J.Y.; Hartl, F.U.; Hayer-Hartl, M. Plant Rubisco assembly in E. coli with five chloroplast chaperones including BSD2. Science 2017, 358, 1272-1278. [CrossRef]

38. Whitney, S.M.; Sharwood, R.E. Plastid transformation for Rubisco engineering and protocols for assessing expression. Methods Mol. Biol. 2014, 1132, 245-262.

39. Blayney, M.; Whitney, S.; Beck, J. NanoESI mass spectrometry of Rubisco and Rubisco activase structures and their Interactions with nucleotides and sugar phosphates. J. Am. Soc. Mass Spectrom. 2011, 22, 1588-1601. [CrossRef]

40. Wilson, R.H.; Alonso, H.; Whitney, S.M. Evolving Methanococcoides burtonii archaeal Rubisco for improved photosynthesis and plant growth. Sci. Rep. 2016, 6, 22284. [CrossRef]

41. Kane, H.J.; Viil, J.; Entsch, B.; Paul, K.; Morell, M.K.; Andrews, T.J. An improved method for measuring the $\mathrm{CO}_{2} / \mathrm{O}_{2}$ specificity of ribulosebisphosphate carboxylase-oxygenase. Aust. J. Plant Physiol. 1994, 21, 449-461. [CrossRef]

42. Sharwood, R.E.; von Caemmerer, S.; Maliga, P.; Whitney, S.M. The catalytic properties of hybrid Rubisco comprising tobacco small and sunflower large Subunits mirror the kinetically equivalent source Rubiscos and can support tobacco growth. Plant Physiol. 2008, 146, 83-96. [CrossRef] [PubMed]

43. Satagopan, S.; Scott, S.S.; Smith, T.G.; Tabita, F.R. A Rubisco mutant that confers growth under a normally "inhibitory" oxygen concentration. Biochemistry 2009, 48, 9076-9083. [CrossRef] [PubMed]

44. Satagopan, S.; Tabita, F.R. Rubisco selection using the vigorously aerobic and metabolically versatile bacterium Ralstonia eutropha. FEBS J. 2016, 2869-2880. [CrossRef] [PubMed] 
45. Knight, S.; Andersson, I.; Brändén, C. Crystallographic analysis of ribulose 1,5-bisphosphate carboxylase from spinach at 2.4 A resolution. Subunit interactions and active site. J. Mol. Biol. 1990, 215, 113-160. [CrossRef]

46. Ramage, R.T.; Read, B.A.; Tabita, F.R. Alteration of the alpha helix region of cyanobacterial ribulose 1,5-bisphosphate carboxylase/oxygenase to reflect sequences found in high substrate specificity enzymes. Arch. Biochem. Biophys. 1998, 349, 81-88. [CrossRef] [PubMed]

47. Furbank, R.T.; Sage, R.F. Editorial overview: Physiology and metabolism: CO2 concentrating mechanisms in photosynthetic organisms: Evolution, efficiency and significance for crop improvement. Curr. Opin. Plant Biol. 2016, 31, iv-vii. [CrossRef]

48. Hasse, D.; Larsson, A.M.; Andersson, I. Structure of Arabidopsis thaliana Rubisco activase. Acta Crystallogr. D Biol. Crystallogr. 2015, 71, 800-808. [CrossRef]

49. Van Lun, M.; van der Spoel, D.; Andersson, I. Subunit interface dynamics in hexadecameric rubisco. J Mol. Biol. 2011, 411, 1083-1098. [CrossRef]

50. Romero, P.A.; Arnold, F.H. Exploring protein fitness landscapes by directed evolution. Nat. Reviews. Mol. Cell Biol. 2009, 10, 866-876. [CrossRef]

51. You, L.; Arnold, F.H. Directed evolution of subtilisin E in Bacillus subtilis to enhance total activity in aqueous dimethylformamide. Protein Eng. Des. Sel. 1996, 9, 77-83. [CrossRef]

52. Vitlin Gruber, A.; Feiz, L. Rubisco Assembly in the Chloroplast. Front. Mol. Biosci. 2018, 5, 24. [CrossRef] [PubMed]

53. Wilson, R.H.; Hayer-Hartl, M. Complex chaperone dependence of Rubisco biogenesis. Biochemistry 2018, 57, 3210-3216. [CrossRef] [PubMed]

54. Whitney, S.M.; Birch, R.; Kelso, C.; Beck, J.L.; Kapralov, M.V. Improving recombinant Rubisco biogenesis, plant photosynthesis and growth by coexpressing its ancillary RAF1 chaperone. Proc. Natl. Acad. Sci. USA 2015, 112, 3564-3569. [CrossRef] [PubMed]

55. Whitney, S.M.; Sharwood, R.E. Linked Rubisco subunits can assemble into functional oligomers without impeding catalytic performance. J Biol. Chem. 2007, 282, 3809-3818. [CrossRef] [PubMed]

56. Conlan, B.; Whitney, S. Preparing Rubisco for a tune up. Nat. Plants 2018, 4, 12-13. [CrossRef]

57. Wilson, R.H.; Thieulin-Pardo, G.; Hartl, F.-U.; Hayer-Hartl, M. Improved recombinant expression and purification of functional plant Rubisco. FEBS Lett. 2019, 593, 611-621. [CrossRef] [PubMed]

58. Cai, Z.; Liu, G.; Zhang, J.; Li, Y. Development of an activity-directed selection system enabled significant improvement of the carboxylation efficiency of Rubisco. Prot. Cell 2014, 5, 552-562. [CrossRef] 